\title{
Overview of Transonic to Hypersonic Stage Separation Tool Development for Multi-Stage-To-Orbit Concepts
}

\author{
Kelly J. Murphy*, Pieter G. Buning ${ }^{\dagger}$, Bandu N. Pamadi ${ }^{\star}$, William I. Scallion§, Kenneth M. Jones ${ }^{* *}$ \\ NASA Langley Research Center \\ Hampton, VA 23681
}

\begin{abstract}
An overview of research efforts at NASA in support of the stage separation and ascent aerothermodynamics research program is presented. The objective of this work is to develop a synergistic suite of experimental, computational, and engineering tools and methods to apply to vehicle separation across the transonic to hypersonic speed regimes. Proximity testing of a generic bimese wing-body configuration is on-going in the transonic (Mach numbers 0.6, 1.05, and 1.1), supersonic (Mach numbers 2.3, 3.0, and 4.5) and hypersonic (Mach numbers 6 and 10) speed regimes in four wind tunnel facilities at the NASA Langley Research Center. An overset grid, Navier-Stokes flow solver has been enhanced and demonstrated on a matrix of proximity cases and on a dynamic separation simulation of the bimese configuration. Steady-state predictions with this solver were in excellent agreement with wind tunnel data at Mach 3 as were predictions via a Cartesian-grid Euler solver. Experimental and computational data have been used to evaluate multi-body enhancements to the widely-used Aerodynamic Preliminary Analysis System, an engineering methodology, and to develop a new software package, "SepSim," for the simulation and visualization of vehicle motions in a stage separation scenario. Web-based software will be used for archiving information generated from this research program into a database accessible to the user community. Thus, a framework has been established to study stage separation problems using coordinated experimental, computational, and engineering tools.
\end{abstract}

\section{Nomenclature}

$\begin{array}{ll}\mathrm{B}_{\text {ref }} & =\text { lateral reference length, in } \\ \mathrm{C}_{\mathrm{A}} & =\text { axial-force coefficient } \\ \mathrm{C}_{\mathrm{i}, \mathrm{b}} & =\text { Sepsim aerodynamic coefficient } \\ \mathrm{C}_{\mathrm{i}, \mathrm{int}} & =\text { Sepsim proximity aerodynamic coefficient } \\ \mathrm{C}_{\mathrm{m}} & =\text { pitching-moment coefficient } \\ \mathrm{C}_{\mathrm{N}} & =\text { normal-force coefficient } \\ \mathrm{F}_{\mathrm{i}} & =\text { representative aerodynamic force } \\ \mathrm{k}_{1} & =\text { Sepsim interpolation factor } \\ \mathrm{L}_{\mathrm{ref}} & =\text { longitudinal reference length, in } \\ \mathrm{M} & =\text { Mach number } \\ \mathrm{q} & =\text { dynamic pressure, psia } \\ \mathrm{S}_{\mathrm{ref}} & =\text { vehicle reference area, in } \\ \mathrm{t} & =\text { time, sec }\end{array}$

\footnotetext{
* Aerospace Engineer, Aerothermodynamics Branch, Mail Stop 408A

$\uparrow$ Aerospace Engineer, Configuration Aerodynamics Branch, Mail Stop 499, AIAA Associate Fellow.

+ Aerospace Engineer, Vehicle Analysis Branch, Mail Stop 365, AIAA Associate Fellow.

$\S$ Aerospace Engineer, Aerothermodynamics Branch, Mail Stop 408A

** Aerospace Engineer, Aerothermodynamics Branch, Mail Stop 408A, AIAA Senior Member.
}

This material is declared a work of the U.S. Government and is not subject to copyright protection in the United States. Published by the American Institute of Aeronautics and Astronautics, Inc., with permission. 


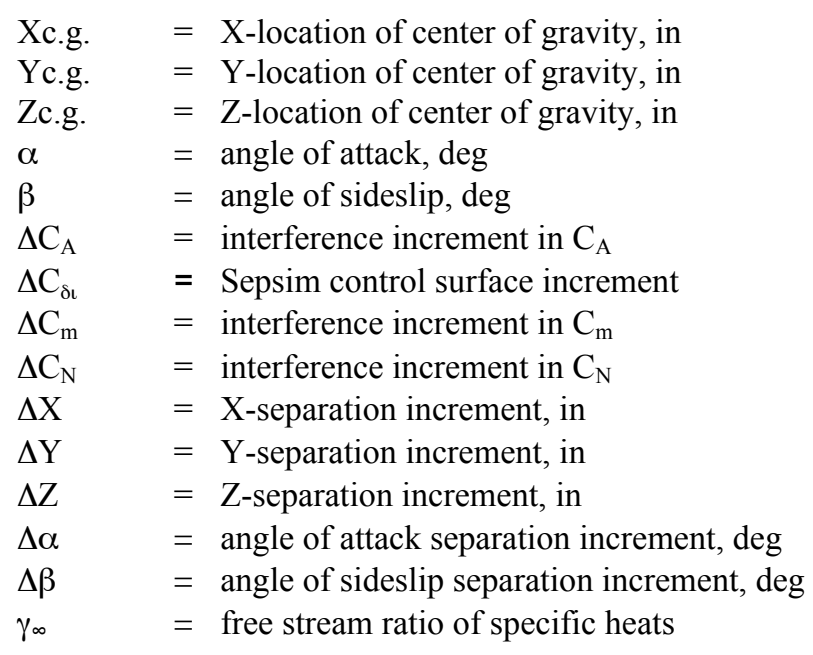

\section{Introduction}

NASA's Integrated Space Transportation Plan (ISTP) provides a comprehensive, long-term strategy to meet future launch vehicle and technology needs combined with reduced cost and improved safety and reliability. Given the current technology levels in the areas of propulsion, structures, and materials, the technical risk for Single-StageTo-Orbit (SSTO) remains high, and now advanced Reusable Launch Vehicle (RLV) design attention has returned to Two-Stage-To-Orbit (TSTO) concepts. While the TSTO concepts being considered range greatly with respect to orbiter/booster shape, propulsion system characteristics, and resulting nominal flight trajectories, all TSTO configurations present a critical need to enhance the knowledge base in two-body separation characteristics within the sensible atmosphere to satisfy both design and abort separation scenarios. The present work provides an overview of the research efforts at NASA to develop the tools and methodologies suitable for system-level analysis of stage separation events. While this effort was initiated several years ago to satisfy specific requirements in the former Next Generation Launch Technology (NGLT) program, ${ }^{1}$ the tools and methodologies being developed are generic in nature and are applicable to broad range of launch vehicles/architectures in NASA's new Space Exploration Initiative.

The goal for stage separation analysis tools is to accurately predict the separation trajectory of a given multivehicle system and the accompanying vehicle loads and control system requirements. Separation is a dynamic process involving a number of disciplines such as steady and unsteady aerodynamics, propulsion, mechanism kinematics, mass characteristics, and atmospheric conditions. The generation and synthesis of these data are generally accomplished by means of selected combinations of experimental, computational, and engineering methods of varying fidelity. Wind tunnel testing is the primary means of generating static vehicle (isolated and proximity) aerodynamic characteristics. These data are directly input into a six-degree-of-freedom trajectory simulation program, typically employing a Monte-Carlo-type simulation of the parameter space, to develop a corresponding set of separation trajectories. Inviscid and viscous computational methods are used both to confirm and/or correct wind tunnel-derived static data and to extend the relevant flow and/or geometric parameter space in order to further refine these trajectory analyses. As a final step for a specific separation scenario, computational methods are used to model the unsteady motion of the vehicles, simulating a dynamic separation process. The development and coordination of the aforementioned classes of analysis tools are the focus of this work.

\section{Objectives}

Research engineers at the Langley Research Center (LaRC), with support from NASA personnel at the Marshall Space Flight Center (MSFC) and the Johnson Space Center (JSC), are developing tools and methods to address aerothermodynamic issues relevant to stage/abort separation. The research program described herein has the following objectives:

(1) Development of a synergistic suite of experimental, computational, and engineering tools and methods with improved robustness and fidelity to provide vehicle designers input on separation characteristics in all phases of configuration development. Experimental tool development involves proximity testing of representative next-generation TSTO configurations in the transonic, supersonic and hypersonic speed regimes provided by four 
LaRC wind tunnel facilities. These tests involve generation of exploratory static aerodynamic, surface pressure, and surface heating data on generic bimese wing-body configurations (to be described in the following section). Specially designed separation support hardware and specifically scaled models have been fabricated to accomplish this testing, and will be described in detail in subsequent sections. The computational tool development activity includes the merging of a six-degree-of-freedom moving-body capability into the OVERFLOW-D flow solver with enhanced features of the standard OVERFLOW code, resulting in a more efficient static and dynamic, viscous multi-body simulation capability. Comparison with results from a Cartesian grid Euler code illustrates both the range of applicability and the speed and ease-of-use of each method in the simulation of staging events. Engineering tool enhancements are sought through modifications to the Aerodynamic Preliminary Analysis System (APAS) and the development of software called "SepSim" for the simulation and visualization of vehicle motions in a stage separation scenario.

(2) Organization and archiving of data generated from the tools validated in the current program on generic and/or candidate TSTO configurations into a user database to gain insight and develop expertise into stage separation characteristics of like configurations. The web-based software AEROCOMPASS, developed and widely used at LaRC, provides an excellent platform for data archival. In addition to a complete description of the configurations tested, all experimental, computational, and system analysis data will be commonly formatted and reside at a single website location to facilitate user access.

\section{Previous Work}

Studies of the aerodynamics of separating bodies have been performed for decades, thus experimental and computational tools currently exist to generate and utilize this type of data. For example, research to examine store separation problems have yielded validated methodologies that have been successfully applied to an array of flight vehicles. ${ }^{2}$ The store separation problem differs from the current topic by the simplification that, in general, only the aerodynamic characteristics of the smaller, external store are significantly disturbed from nominal conditions. The study of the parallel separation of similar-sized lifting stages also has a well-documented legacy. Some of the earliest work was initiated by the Air Force in 1959-1960 in their reusable booster studies. ${ }^{3}$ NASA followed in the early 1960s as the nation began its quest for a reusable launch vehicle system. The reader is referred to the extensive work of Decker, et al., initiated in the early 1960s and continuing through the mid-1970s. ${ }^{3-6}$ In this program proximity testing was conducted on both simple shapes and typical TSTO configurations at supersonic and hypersonic conditions to develop the necessary experimental tools to generate aerodynamic proximity data as well as to understand the nature of support interference effects. Data generated from these studies were then input into a six-degree-of-freedom dynamic simulation program in order to simulate resulting flight trajectories. Although the final design that emerged as the Space Shuttle in the early 1970s did not have parallel lifting stages, the methodologies developed in these early separation studies laid an important foundation for the booster separation work $^{7,8}$ that was required to develop the current multi-stage system.

In the 1980s, post Shuttle development, NASA continued to examine earth-to-orbit space transportation concepts to cover a wide range of mission requirements. System analysis studies continued to examine two-stage, fully reusable systems. ${ }^{9,10}$ Following the accidental loss of the Shuttle Challenger on ascent in 1986, a focused program employing experimental and system analysis tools was initiated to look at Shuttle Orbiter boost-phase abort scenarios, i.e. separation of the orbiter from the external tank on ascent. ${ }^{11,12}$ As mentioned previously, the 1990s saw the majority of activity in RLV development focused on single-stage-to-orbit concepts in hopes of improving safety and reliability and reducing cost. With SSTO deemed too risky with current technologies, RLV studies have again returned to multi-stage systems. With continual advances in computing power, computational fluid dynamic (CFD) tools have now become viable to confirm and extend experimental studies in the area of separation aerodynamics. ${ }^{13}$ The work described herein represents a new level of coordination of both existing and new experimental, CFD, and engineering methods to develop a suite of synergistic tools to analyze aerodynamic separation issues from transonic to hypersonic conditions.

\section{Configuration Description}

In order to coordinate the tool development effort, the same generic two-stage configuration was used as the test bed for all experimental, computational, and engineering stage separation work. The Langley Glide-Back Booster (LGBB), in a belly-to-belly, bimese configuration is shown in Figure 1. The LGBB is a generic wing-body configuration that was developed by Langley Research Center's Vehicle Analysis Branch for in-house multi-stage 

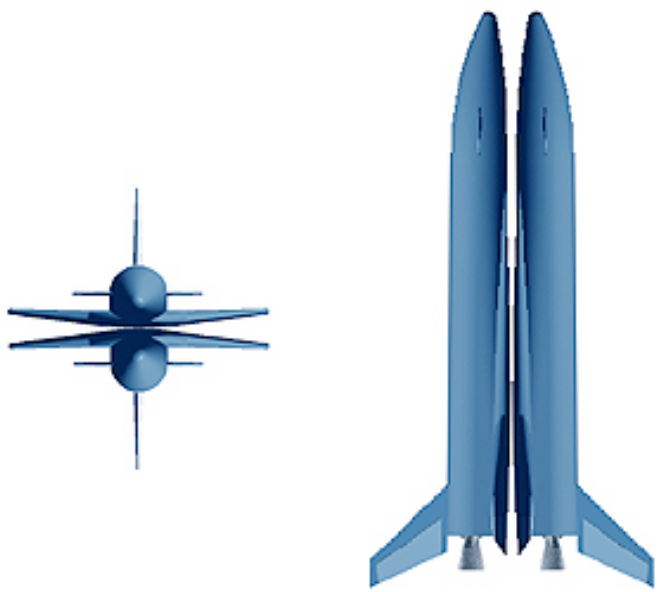

Figure 1. LGBB Bimese Arrangement launch vehicle system-analysis studies. The ability to leverage off of this earlier work was the primary driver in the selection of this particular wing-body configuration.

Figure 2 shows a detailed planform schematic of the L G B B . Th e configuration has an 82.3-inch diameter cylindrical fuselage with a drooped, 11.2inch-radius nose. The length from the tip of the nose to the base of the body (i.e. the engine exit plane) is 750 inches. The wing/strake is a NACA 2300 series airfoil at a 6-degree dihedral angle; the strake is swept 81.1 degrees and the wing is swept 45.3 degrees. The wing's forward swept trailing edge is a full-span elevon pair separated by a center body flap. The configuration has a center vertical tail with a leading edge sweep angle of 45 degrees. The tail's airfoil section, including a trailing edge rudder, is a NACA 0013 airfoil and its span is 110.2 inches. The baseline LGBB vehicle includes a swept canard, NACA 64A012 airfoil, located on the forward part of the fuselage; however, canards were not used in the two-stage bimese configuration. Reference dimensions for the full-scale LGBB vehicle, as well as wind tunnel models tested in the present study, are included in Table 1.

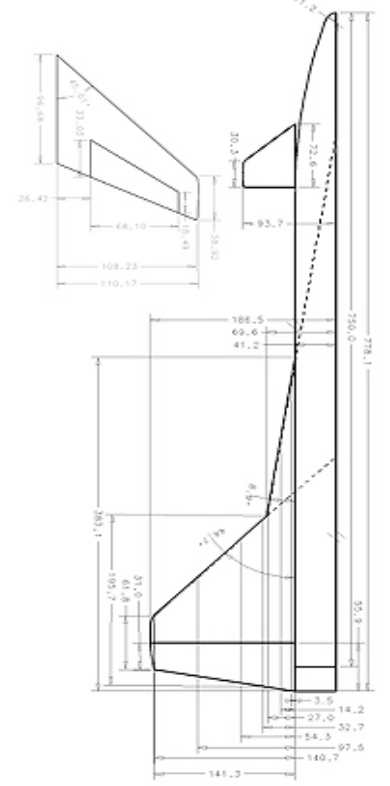

Figure 2. Planform Schematic of the LGBB Vehicle

Table 1. Reference Dimensions for LGBB

\begin{tabular}{|c|c|c|c|c|}
\hline $\begin{array}{l}\text { Reference } \\
\text { Dimension }\end{array}$ & $\begin{array}{l}\text { Full-Scale } \\
\text { Flight } \\
\text { Vehicle }\end{array}$ & $\begin{array}{l}.0273-\text { Scale } \\
\text { (Transonic } \\
\text { Test Model) }\end{array}$ & $\begin{array}{l}.0175-S c a l e \\
\text { (Supersonic } \\
\text { Test Model) }\end{array}$ & $\begin{array}{l}\text { 0.0121-Scale } \\
\text { (Hypersonic } \\
\text { Test Model) }\end{array}$ \\
\hline Sref & 62640 in $^{2}$ & 46.69 in $^{2}$ & 19.18 in $^{2}$ & 9.15 in $^{2}$ \\
\hline Lref & 750 in & 20.48 in & 13.13 in & 9.06 in \\
\hline Bref & 369 in & 10.07 in & 6.46 in & 4.46 in \\
\hline Xc.g. $(68 \% *$ Lref) & 510 in & 13.92 in & 8.93 in & 6.16 in \\
\hline Yc.g. & $0 \mathrm{ft}$ & 0 in & 0 in & 0 in \\
\hline Zc.g. & $\mathbf{0} \mathbf{f t}$ & 0 in & 0 in & 0 in \\
\hline
\end{tabular}

While it is possible that there could be various sizing and arrangements of these stages, it was observed that a bimese, belly-to-belly, wing-body TSTO configuration would provide a worst case in wing-to-wing proximity effects, known to provide significant aerodynamic interference. The expectation is that if the tools can be exercised and validated for a bimese, belly-to-belly configuration, other flow fields of lesser complexity and loading will also be amenable to analysis. The authors recognize that proximity effects are extremely configuration dependent, and thus any assumptions about interference data on configurations other than the one currently under study need to be examined carefully.

\section{Experimental Program}

As part of developing experimental stage separation tools, exploratory proximity testing has been performed across the transonic to hypersonic speed regimes in three wind tunnel facilities at the Langley Research Center, with initial screening data from a supersonic facility at the Marshall Space Flight Center. ${ }^{14}$ While proximity testing had been done in the past in some of these facilities, no coordinated collection of experimental infrastructure existed to 
work nominal/abort separation issues from transonic through hypersonic conditions in a coordinated effort with the development of computational and engineering tools. As highlighted earlier, the re-emergence of TSTO concepts has been the impetus for development of these tools.

Clearly, two-body proximity testing is a much more complex undertaking than single-body testing. While issues such as instrumentation and model accuracy, flow modeling limitations (e.g. viscous, real gas effects), and tunnel performance (flow quality/uniformity) are just as relevant, other factors may present even greater problems for twobody systems. Proximity increments may be very small compared with full-scale aerodynamic loads (but nevertheless important with respect to a vehicle's stability and control characteristics in a separation maneuver) and highly non-linear and configuration dependent. Support interference and positioning accuracy are of extreme concern with the hardware required to locate one model in proximity to another. This study seeks to address, for each speed regime, the aforementioned issues in order to assess the ability to generate credible static stage separation data for like-scale, two-stage configurations with existing testing infrastructure at LaRC. The testing performed to date is considered exploratory in nature, with the expectation of building a better understanding of testing methodologies in these facilities and flow physics related to these configurations. The following sections serve to give the reader an overview of the test program in each speed regime. Samples of qualitative results are presented for each test program. Detailed quantitative discussion of proximity results is outside the scope of this work and will be presented in future reports.

\section{(1) Supersonic Testing}

For the bimese LGBB configuration chosen for these separation studies, the nominal staging condition is Mach 3. Thus separation testing was first initiated in the supersonic regime in Langley's Unitary Plan Wind Tunnel (UPWT).

Facility - LaRC Unitary Plan Wind Tunnel ${ }^{15}$ : The UPWT is a closed-circuit, continuous-running, pressure tunnel with two test sections that are nominally $4 \mathrm{ft}$ by $4 \mathrm{ft}$ in cross section and seven $\mathrm{ft}$ long. The stagnation pressure can be varied up to a maximum of approximately 50 psia in Test Section I and approximately 100 psia in Test Section II. The nozzle throat-to-test-section area ratio is varied by a lower asymmetric sliding nozzle block that provides continuous variation of the Mach number. The Mach number range is nominally 1.5 to 2.86 in Test Section I and 2.3 to 4.63 in Test Section II. Tunnel stagnation temperatures are typically $125^{\circ} \mathrm{F}$ and $150{ }^{\circ} \mathrm{F}$ for each test section, respectively. Reynolds numbers from 1.0 to 5.0 million per foot can be run routinely with a capability to reach 6.0 million per foot on a transient basis. The basic model support mechanism is a horizontal wall-mounted strut that is capable of forward and aft travel of over $3 \mathrm{ft}$ in the streamwise direction. A main sting support attached to the strut can transverse laterally \pm 20 in and can provide a yaw capability of $\pm 12^{\circ}$. Forward of the main sting support is the angle-of-attack mechanism that provides pitch motion from $-15^{\circ}$ to $+30^{\circ}$. A roll mechanism can be installed ahead of the pitch mechanism to provide continuous roll motion over a $310^{\circ}$ range.

Separation Hardware/Tunnel Modifications: Proximity testing on the LGBB bimese configuration was only conducted in Test Section II of the UPWT, with test conditions summarized in a subsequent section. The UPWT wind tunnel is an excellent facility for proximity testing due to the existing fore/aft/lateral translation and angular rotation capability of its main support strut. While the translation capability was designed to optimally position a model in the test section for testing at a single location, the staff at the UPWT, through an extensive testing and calibration process and significant modifications to their control and data acquisition systems, were able to develop an extremely accurate system of single-body movement during a tunnel run.

With the ability to accurately move a single-body within the test section, only a second model mounted in the test section at a fixed attitude and location was required to do proximity testing in the UPWT. This allowed separation testing to be initiated in this facility with a minimum of hardware costs. Due to restrictions on the floor and ceiling of the tunnel, the tunnel sidewall was deemed the best location for a fixed support strut. This required replacing one of the glass sidewalls, in place to obtain Schlieren flow field images, with a solid sidewall. (Eliminating Schlieren capability was an unfortunate consequence to this test set-up, and alternative mounting arrangements or flow visualization techniques should be examined for future testing.) A fixed-position support strut, shown in Fig. 3, was designed and fabricated by Advanced Technologies Incorporated in Newport News, VA. The all-stainless-steel support strut consists of two pieces: a rectangular mounting plate and a fixed-angle blade strut. The interface between the two parts includes a series of holes for \pm 3 degree angular adjustment in increments of 0.1 degree. The strut arm is a wedge-slab-wedge shape at a 60-degree sweep angle designed to withstand aerodynamic loads with minimum interference. The strut is designed to receive a designated LaRC force and moment balance on which a model is mounted for aerodynamic measurements. The complete strut assembly locates the balance centerline at 18 inches off of the tunnel sidewall at zero degree pitch, roll, and yaw angles. 
Model Hardware/Instrumentation: Two 1.75\%-scale (approximately 13.1-inch long) stainless steel force models were fabricated in the LaRC machine shop for separation testing in the UPWT (Fig. 4). The reference areas and
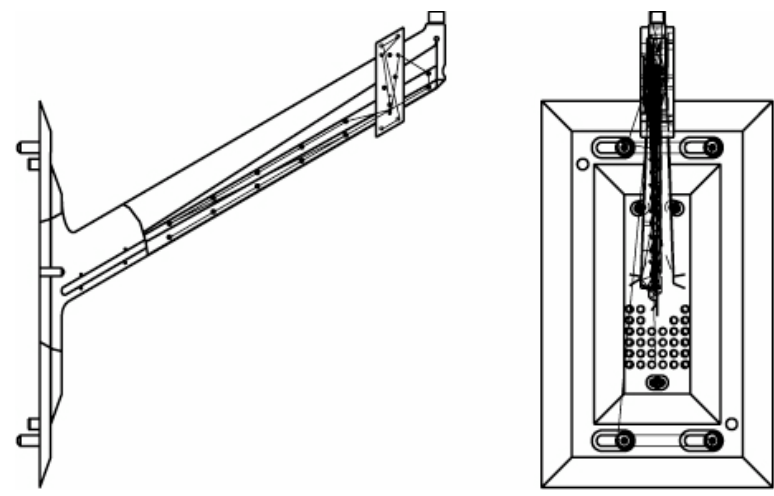

Figure 3. Fixed-position support strut designed for LaRC Unitary Plan Wind Tunnel

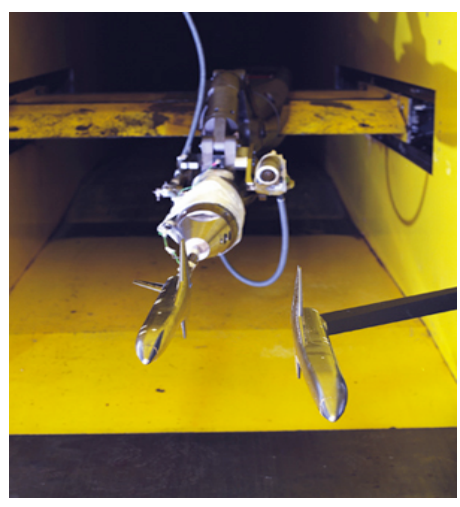

Figure 4. LGBB Models Installed in the LaRC UPWT Wind Tunnel

lengths used to calculate aerodynamic coefficient data for the full-scale vehicle and the 0.0175 -scale models are presented in Table 1. Both models, one designated as the "orbiter" (forward-positioned model) and one designated as the "booster" (aft-positioned model) were designed to receive a Langley 6-component force and moment balance. All aerodynamic data were taken in a pitch-pause mode and corrected real-time for support system deflection under loading. The orbiter model was also instrumented with 13 windward static pressure taps on the fuselage centerline and the wing mid-span. Base and cavity static pressure measurements were made for both models. The orbiter model was mounted with wings vertical (parallel to the tunnel sidewalls) on the fixed support strut, with a slot machined in the model leeside in place of the vertical tail to accommodate the blade exiting the model. The booster model was mounted with wings vertical on the main tunnel support on a straight sting that exited the model base. Translation and rotation capability of the tunnel's main support allowed the booster model to be moved in proximity to the fixed orbiter model. The matrix of proximity locations and orientations is described below.

Test Parameters: With the tunnel capability and model hardware and instrumentation described above, LGBB aerodynamic and surface pressure proximity data was obtained over a range of geometric separation parameters and Mach numbers. Figure 5 is a schematic that shows the models mounted in the UPWT with the range of longitudinal $(\square \mathrm{X})$ and vertical $(\square \mathrm{Z})$ separation values tested for the bimese belly-to-belly configuration. Figure 6 is more detailed

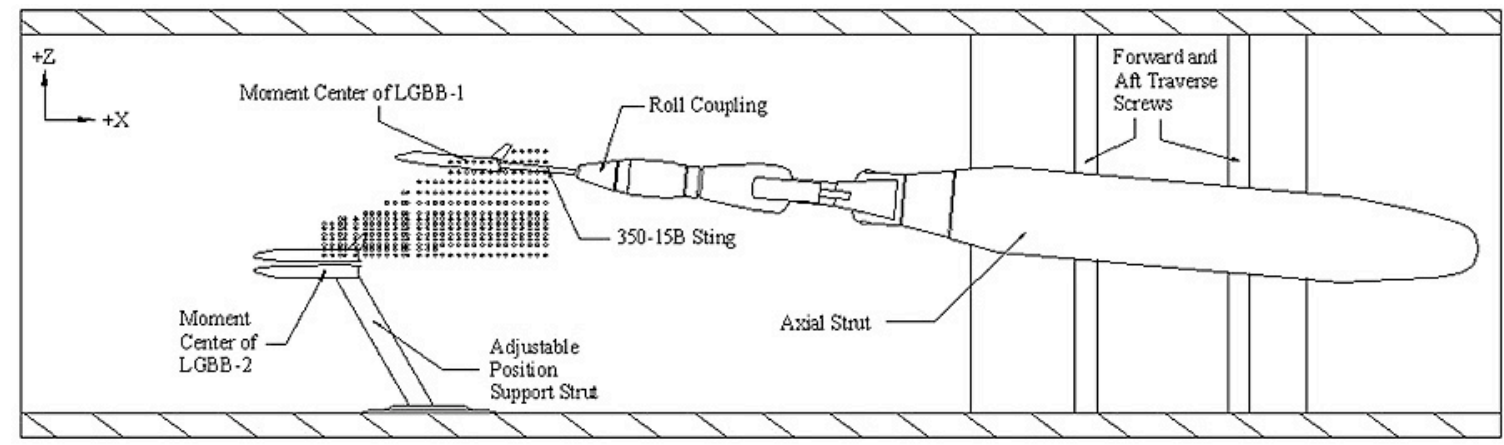

Figure 5. Schematic of LGBB in UPWT with proximity matrix

schematic showing the specific values of $\square \mathrm{X}$ and $\square \mathrm{Z}$ separation locations tested. With the orbiter model fixed, the booster model was moved through this matrix of $\square \mathrm{X}$ and $\square \mathrm{Z}$ locations at an angle of attack of 0 deg and 5 deg for Mach numbers of 2.3, 3.0 and 4.5 in a belly-to-belly orientation, the primary configuration of interest described above. As a secondary configuration, the booster model, with vertical tail removed, was rolled 180 degrees and a matrix of back-to-belly data was also obtained for the same matrix of separation locations and Mach numbers. Isolated data was also obtained for both booster configurations throughout the test space as well as isolated data on the orbiter at its fixed location. Repeat runs were focused at various separation locations and spaced throughout the 
course of the testing (three entries) to provide a measure of within test and test-to-test repeatability to aid in uncertainty estimates.

Comments: The above test parameters have provided a large proximity database for the LGBB bimese configuration at supersonic test conditions. Over 5,000 proximity data points were taken in three entries in the UPWT. A detailed discussion of quantitative results will not be presented herein, but some examples of information derived from the data are shown in Figure 7 (and again later in the text) to give the reader a qualitative sense of the type of results obtained in these tests. Figure 7 shows the same $\square \mathrm{X}-\square \mathrm{Z}$ separation matrix shown in Figure 6, but now it is shaded to show the regions of influence of the

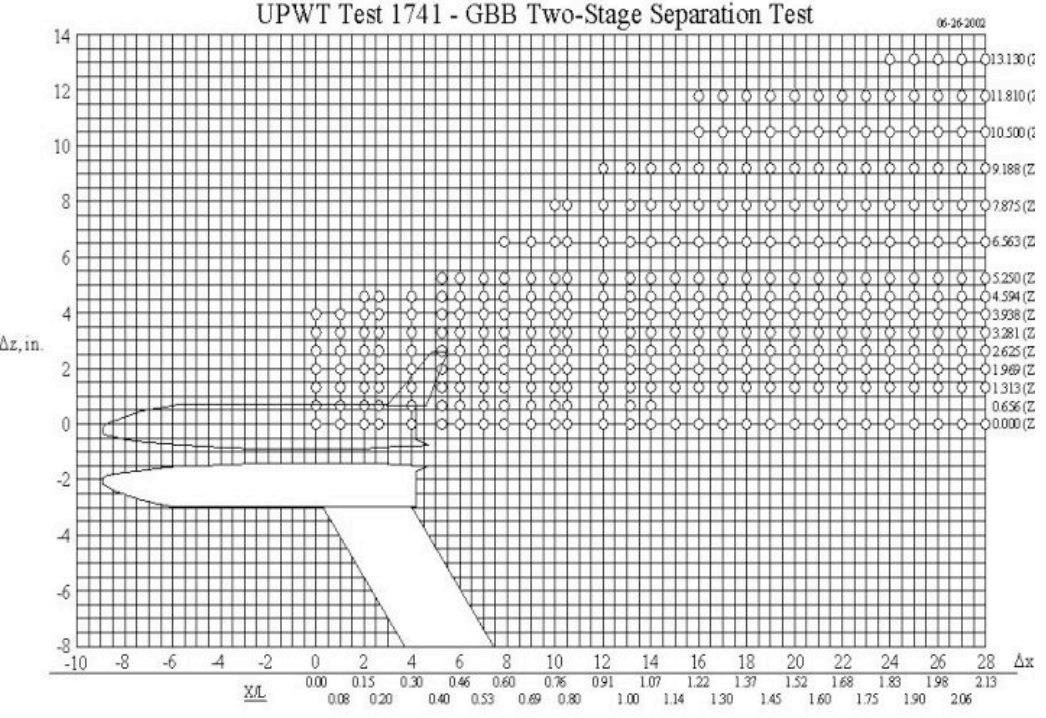

Figure 6. Detailed Schematic of LGBB proximity matrix in the UPWT

booster on the orbiter's aerodynamics in a belly-to-belly configuration at $\mathrm{M}=2.3, \mathrm{M}=3.0$, and $\mathrm{M}=4.5$ for booster angles of attack of 0 and 5 degrees. As expected, these plots show a decreasing region of influence with increasing Mach numbers as shock angles become steeper. Similar plots for the booster (not shown) show the region of influence of the orbiter on

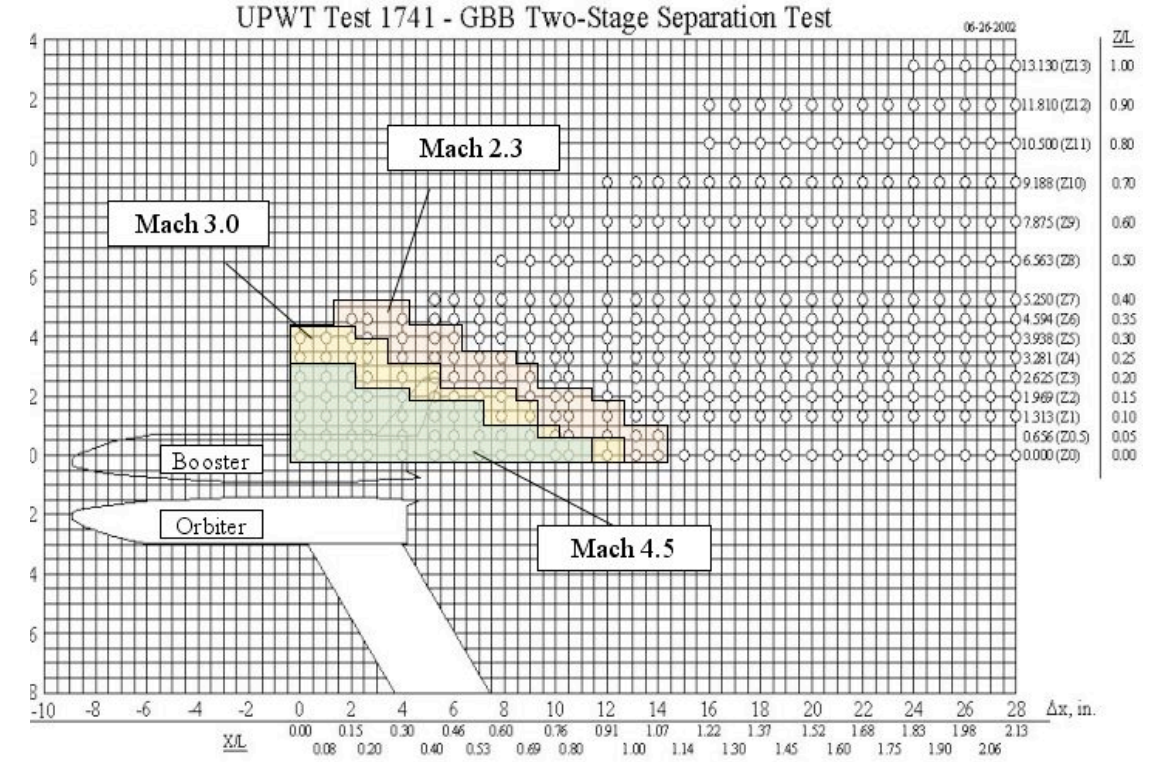

\section{Figure 7. Region of aerodynamic influence of the booster on the orbiter at Mach 2.3, 3, and 4.5} 6, with aeroheating tests at Mach 6 (these tests will leverage off of separation hardware developed for aerodynamic testing but will not be further discussed in this overview) and aerodynamic tests at Mach 10 scheduled for later this year. The authors recognize that proximity testing at hypersonic Mach numbers would satisfy neither abort nor booster aerodynamics to be significantly larger, and only at the largest values of $\square \mathrm{Z}$ at the highest Mach number was there evidence of interference-free data on the booster. Additional Mach 3 proximity data from this test series will be presented and discussed in the computational methods section to follow.

\section{(2) Hypersonic Testing}

Soon after proximity testing was initiated at supersonic conditions, similar tests were planned at hypersonic conditions in two facilities in the Langley Aerothermodynamic Laboratory (LAL). ${ }^{16}$ At the time of this writing, aerodynamic proximity tests have been completed at Mach 
nominal stage separation conditions for a bimese configuration (the booster would be larger than the orbiter for a two-stage system with a nominal/abort separation Mach number of 6 or higher). However, for the purposes of tool development and code calibration, the bimese LGBB will provide suitable data and allow for comparison of aerodynamic proximity data across the speed regime.

Facility - LaRC 20-Inch Mach 6 Air Tunnel ${ }^{16}$ : This facility, which became operational in 1958, is a blow-down wind tunnel that uses heated, dried, filtered air as the test gas. A fixed-geometry, two-dimensional contoured nozzle is used to generate Mach 6 flow in a test section with 20.5-in by 20-in cross section. Typical run times are 2-10 minutes depending on the requirements of the study and the tunnel running conditions. The tunnel can operate at stagnation pressures from 30 to $500 \mathrm{psi}$ and stagnation temperatures from 750 to $1000{ }^{\circ} \mathrm{R}$, corresponding to freestream Mach numbers from 5.8 to 6.1 and unit Reynolds numbers from 0.5 to 9 million per foot. Test core size, as defined by a maximum of $\pm 1.0 \%$ variation in pitot pressure, varies from approximately $12 \times 12$ in to $14 \times 14$ in as free stream Reynolds number increases. The normal shock density ratio for this facility is 5.3 and ideal gas behavior is achieved throughout the tunnel (i.e. $\square=1.4$ everywhere). Models are mounted on an injection system located in a housing below the closed test section. A computer-operated sting support system is capable of moving the model through an angle of attack range of $-5^{\circ}$ to $+55^{\circ}$ for angles of sideslip of $\pm 8^{\circ}$. Model injection times can be as rapid as $0.5 \mathrm{sec}$. (commonly used for heat transfer tests), but generally are set for $1.2 \mathrm{sec}$. to keep model acceleration less than $2 \mathrm{~g}$ to avoid damage to the force balances.

Facility - LaRC 31-Inch Mach 10 Air Tunnel ${ }^{16}$ : Although designed in the 1950s as a blow-down starting, continuously-running facility, the Mach 10 tunnel now operates solely in a blow-down mode and uses heated, dried, filtered air as the test gas. The facility uses a three-dimensional contoured nozzle with a 1.07-in square throat and a 31-in square test section. The Mach 10 tunnel has been calibrated for reservoir pressures from 350 psia to 1450 psia for a stagnation temperature of approximately $1800^{\circ} \mathrm{R}$, which corresponds to a range of freestream unit Reynolds numbers of 0.5 to 2.1 million per ft. The test core varies from about $12 \times 12$ in at the lowest Reynolds number condition to approximately $14 \times 14$ in at the highest value (note that core size is the same as for the Mach 6 tunnel). For aerodynamic testing, models are kept within a \pm 7 in inviscid test region where the pitot pressure distribution varies less than $\pm 1.0 \%$. The normal shock density ratio for this facility is 5.9 , which is naturally higher than the Mach 6 facility and higher than perfect air predictions (the normal shock density ratio for perfect gas is 5.74 for $\mathrm{M}_{\infty}=10$ ) due to vibrational excitation associated with the higher temperatures in this facility. The Mach 10 tunnel can achieve run times of approximately 120 seconds. Models are supported on a hydraulically operated, sidewallmounted injection system and can be injected to the nozzle centerline in less than $0.6 \mathrm{sec}$. (an injection time of 2 seconds is used for force and moment testing). The computer-controlled support strut is able to achieve a pitch range of $-10^{\circ}$ to $+45^{\circ}$ and a sideslip range of $\pm 5^{\circ}$.

Separation Hardware/Tunnel Modifications: As part of a program to examine Shuttle upgrade possibilities in the mid-1990s, the Liquid-Fly-Back-Booster (LFBB) program was initiated as an alternative to Shuttle replacement whereby the expendable solid rocket boosters would be replaced by fully-reusable liquid-fueled boosters that would fly-back to a designated landing site. From 1997 to 1998 the first author of this paper led the design and fabrication of a separation rig for Langley's Mach 6 tunnel and conducted the first ever multi-body separation testing in this facility in support of the LFBB program. An extensive matrix of separation data ( $\square \mathrm{X}, \square \mathrm{Y}, \square \mathrm{Z}, \square, \square$ ) was generated to evaluate several LFBB concepts, but these data remain unpublished. It is the rig fabricated for the LFBB work that was used to accomplish hypersonic proximity testing for the current research effort.

The separation rig was originally designed and fabricated in-house at LaRC with subsequent modifications for LGBB testing done in-house as well. The rig, shown in Figure 9, has two main components, both machined of stainless steel. The central support mates with the tunnel strut head and is comprised of a top cylindrical-holed support (in which a sting/model can be mounted) and a rectangular column extending downward from the top support with a wedge-slab shape. This column has a series of patterned screw holes down its length such that an additional model support structure may be mounted at various Z-distances from the top model. This lower model support piece has plates that provide incremental pitch (ㄱ) and sideslip (ㄷ) capability for the lower model. Longitudinal X-separation is obtained via sliding the top sting to various calibrated, notched locations. This rig allows only manual adjustment of lower model position and thus only one set of separation parameters per tunnel run. As this facility is a blow-down to vacuum with limited run times, the expense and complexity of a remotedriven separation rig was not justified for this exploratory round of tests. 
Model Hardware/Instrumentation: Two 1.21\%-scale (approximately 9.1-inch long) stainless steel force models were fabricated by Allied Aerospace in Newport News, VA. for separation testing in the Mach 6 and Mach 10 facilities (Fig. 9). The reference areas and lengths used to calculate aerodynamic coefficient data for these 0.0121-

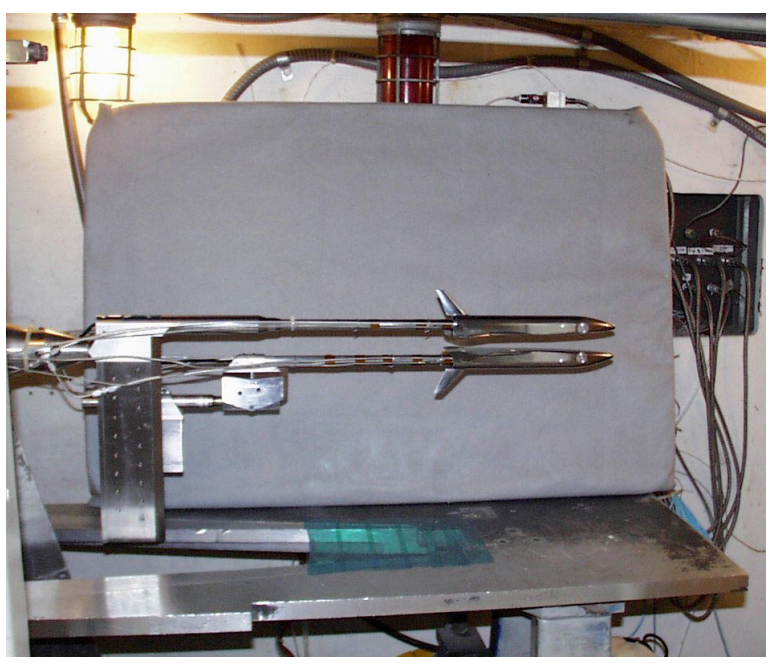

Figure 9. Separation apparatus and models used for proximity testing at Mach 6 scale models are presented above in Table 1. The models, one tested as the "orbiter" and one tested as the "booster," are nominally identical and both designed to receive a Langley 6-component force and moment balance mounted on a straight sting support. All aerodynamic data were taken in a pitch-pause mode and corrected post-run for support system deflection under loading. Base and cavity static pressure measurements were made for both models. The matrix of model attitudes and proximity locations for tests completed in the 20-inch Mach 6 tunnel is described below.

Test Parameters: Figure 10 graphically shows the 86 proximity locations, derived from 11 different $\square \mathrm{X}$ locations and 8 different $\square Z$ locations, for the bimese LGBB configuration tested at Mach 6 in a belly-to-belly orientation. All $\square \mathrm{X}$ movement was achieved by moving the booster (top) model aft of the orbiter (bottom) model. All $\square \mathrm{Z}$ movement was achieved by lowering the orbiter model from the mated position. All $\square \mathrm{X}$ and $\square \mathrm{Z}$ separations were run at $\mathrm{QD}=0$ degrees and 5 degrees At each of the separation locations, both models were simultaneously swept through an angle of attack range of -4 degree to +5 degrees using the tunnel strut angle of attack mechanism. Isolated data were obtained for the orbiter and the booster with and without the presence of the lower model support structure.

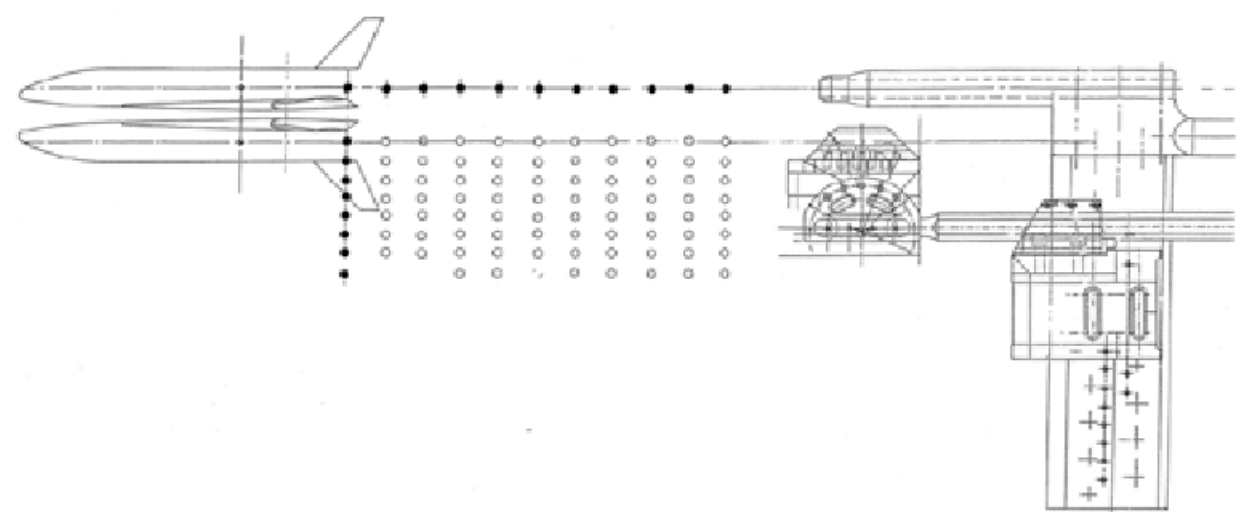

Figure 10. Detailed Schematic of LGBB proximity matrix in the 20-Inch Mach 6 Tunnel

Comments: Over 800 proximity data points were generated for the LGBB bimese configuration in three entries in the 20-Inch Mach 6 Air Tunnel. A test entry in the 31-Inch Mach 10 Air Tunnel is planned for Fall of 2004. A sample of the aerodynamic proximity data at Mach 6 is shown in Figure 11, where the variation of pitching moment with angle of attack for the isolated booster (Run 3), the booster in proximity to the orbiter support hardware (without the orbiter and sting, Run 21), and the booster in proximity to the orbiter and corresponding support hardware (Run 61) are presented. The solid circular symbols represent the isolated booster plus the increment in pitching moment, $\square \mathrm{Cm}$, caused by the presence of the orbiter only. $\left(\square \mathrm{Cm}=\mathrm{Cm}_{\text {Run61 }}-\mathrm{Cm}_{\text {Run21 }}\right)$ It is important to note that the linear superposition of interference effects requires further validation and is cautiously presented here for the purposes of qualitative discussion only. Schlieren photographs were recorded for each angle of attack, with those at -4 deg and 5 deg shown in Fig. 11. At the two negative angles of attack, the pitching moment of the booster is more negative in the presence of the orbiter. The corresponding Schlieren image at -4 deg shows that the orbiter bow shock strikes the booster centerline in the vicinity of the longitudinal center of gravity (c.g.). The increased pressure field between the bow shock and the wing shock (the second shock emanating from the orbiter) is entirely aft of the 

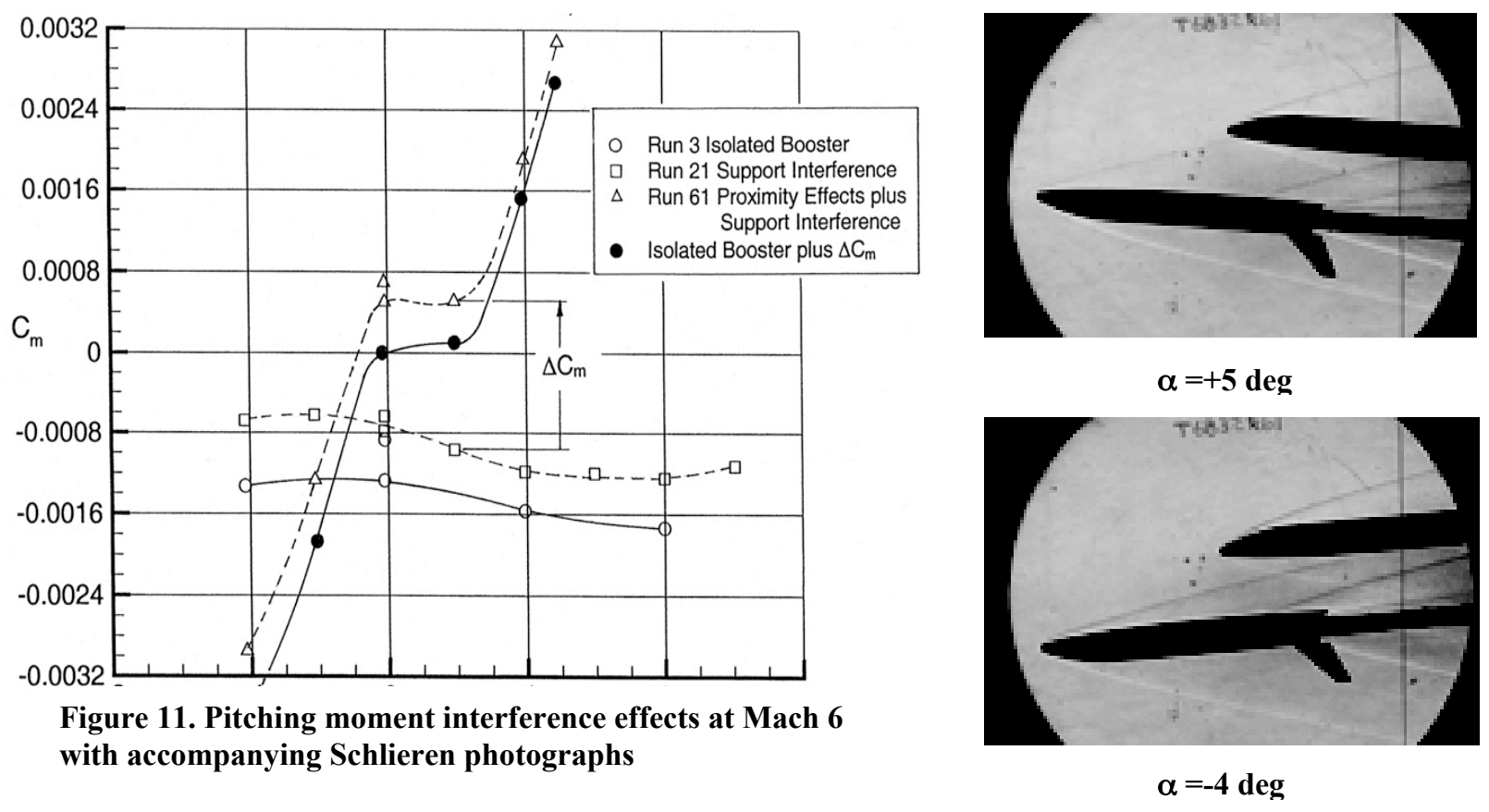

booster c.g. and likely contributes to the negative increment in pitching moment. As the angles of attack of both the booster and orbiter are increased, a progressive forward movement of the orbiter shock pattern on the booster is observed in the Schlieren images (only $\square=5$ deg is shown). As a varies from 0 to 2 degrees, the data indicate that the pressure field is balanced about the booster c.g., and the pitching moment is nearly unchanged. The change in stability over this 0 to 2 degree range cannot quantitatively be explained via Schlieren images, and it is hoped that CFD solutions at these conditions will provide additional insight into interference effects. As the orbiter shocks move forward on the booster with increasing angle of attack, the pitching moment becomes more positive.

\section{(3) Transonic Testing}

The last series of proximity testing initiated at LaRC was in the transonic regime. For candidate TSTO concepts, separation testing is performed at transonic conditions to satisfy a range of abort scenarios on ascent. Transonic testing posed the greatest difficulty due to high loading conditions and the lack of existing tunnel infrastructure (e.g. translation capability of the tunnel main strut) or support hardware. A description of the test program in Langley's 16-FT Transonic Tunnel is presented in the sections that follow.

Facility - LaRC 16-FT Transonic Tunnel ${ }^{17}$ : The 16-FT Transonic Tunnel is a closed circuit, single-return, continuous flow atmospheric tunnel. The test gas is air with an air exchange for cooling. The nominal Mach number range for the facility is 0.2 to 1.3 . Speeds up to Mach 1.05 are obtained with the tunnel main drive fans only; speeds above Mach 1.05 are obtained with combination of the main drive fans and test-section plenum suction via a ninestage axial compressor. The slotted octagonal test section nominally measures 15.5 feet across the flats. The useable test section length is 22 feet for speeds up to Mach 1.0 and 8 feet for speeds above Mach 1.0. The tunnel main support strut has a nominal angular travel of -10 to +25 degrees. The strut head has remote rotary control so that the model and sting can be rolled as a unit from -90 to +90 degrees. Lateral aerodynamic force testing can be done by rolling the model through this \pm 90 -degree range and traversing the main tunnel support system in the vertical plane. Generally, model size is dictated by wind tunnel blockage effects at subsonic speeds and boundary-reflected disturbances at supersonic speeds. Blockage and shock reflection criteria for this facility can be found in Ref. 17. Testing is not performed between Mach numbers of 0.98 to 1.05 because of both subsonic and supersonic wall interference effects.

Separation Hardware/Tunnel Modifications: Unlike the supersonic and hypersonic test facilities described in previous sections, no existing tunnel infrastructure or previously fabricated hardware could be utilized to accomplish proximity testing at transonic conditions. Furthermore, modifications to the existing tunnel main support strut to accommodate remote model movement (to take full advantage of the continuous flow facility) were too complex and expensive given programmatic resources. Based on these facility and financial considerations, it was decided to 
build an independent (i.e. not connected to the main support strut) model support system capable of remote-driven two-axis movement.

A contract was awarded to Advanced Technologies Incorporated in Newport News, VA to design and fabricate a support fixture capable of remote actuation in the stream-wise and vertical direction relative to flow in the 16-FT

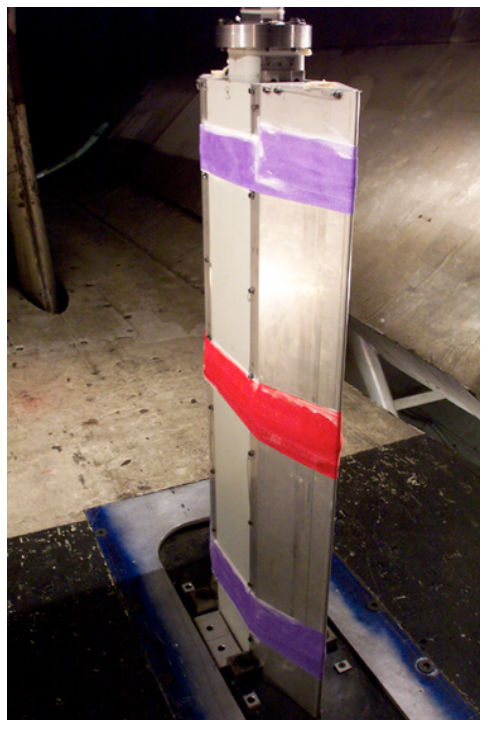

Figure 12. Remote-driven separation rig tested in the 16-Ft Transonic Tunnel

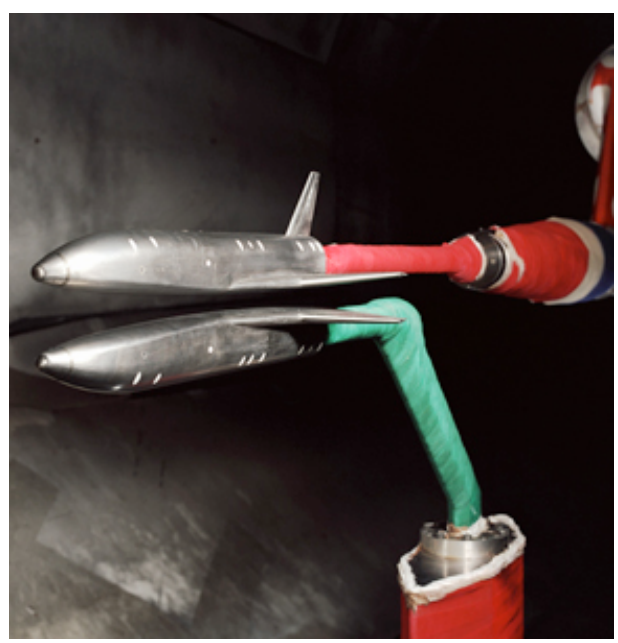

Figure 13. Remote-driven separation rig and $2.73 \%$ LGBB force models tested in the 16-Ft Transonic Tunnel
Tunnel. This fixture was required to mount to the existing semi-span support structure under the tunnel floor. Given the high static and dynamic loading at transonic testing conditions in the 16-FT Tunnel as well as the aforementioned blockage considerations, the design of this support fixture was a trade between maximizing strength while minimizing size. The rig is comprised of a stainless steel column support, on which a force model is mounted, that is encased in an aluminum wedge-slab-wedge fairing cover (Fig. 12). The rig is capable of stream-wise translation of 48 inches and a vertical translation of 30 inches. A fixed blade support strut and a blade/sting combination support strut were fabricated to receive an LGBB model mounted on a specified LaRC force balance atop the fixture. All instrumentation cabling was run internal to the separation fixture. With a model and balance mounted on a straight sting on the main tunnel support, installation of the separation rig with a force model on the tunnel floor permitted a matrix of proximity locations to be tested for two bodies at transonic conditions.

Model Hardware/Instrumentation: Two 2.73\%-scale (approximately 20.5-inch long) stainless steel force models were fabricated by Allied Aerospace Incorporated for separation testing in the 16-FT Transonic Tunnel (Fig. 13). The reference areas and lengths used to calculate aerodynamic coefficient data for these 0.0273 -scale models are presented above in Table 1. Both models were designed to receive specified Langley 6-component force and moment balances. One model was also instrumented with 13 windward static pressure taps on the fuselage centerline and the wing mid-span. Base and cavity static pressure measurements were made for both models. All aerodynamic data were taken in a pitch-pause mode and corrected real-time for support system deflection under loading. Similar to the models designed for testing in the UPWT, one of the transonic models was designed to receive a straight sting support while the other was designed to receive either a blade or a straight sting. Both models were tested alternatively as the "orbiter" and the "booster." (By previous definition the "orbiter" designation had been given to the model tested forward of the pair and the "booster" designation to the model aft of the pair. Because this relative position changed within a run for transonic testing, this test series used the designation "upper" and "lower" for clarity.) The matrix of model attitudes and proximity locations is described below.

Test Parameters: With the specially designed remote-driven support installed in the 16-FT Tunnel, LGBB aerodynamic proximity data was obtained over a range of geometric separation parameters and Mach numbers in a similar fashion to the supersonic test matrix. Points were taken over a rectangular matrix space with $\square \mathrm{Z}$ separation values from 0 (i.e. the mated position) to $11.9 \mathrm{in}$. and $\square \mathrm{X}$ values from -14.1 in. to 14.1 in. With the upper sting-mounted model fixed, the lower blade/sting model mounted on the separation rig was moved through this matrix of $\square \mathrm{X}$ and $\square \mathrm{Z}$ locations for Mach numbers of $0.6,1.05$ and 1.1 in a belly-to-belly orientation. Angle of attack and sideslip variations were run for a selected set of proximity test conditions. Runs were also performed for each model isolated as well as the upper model with only the support strut (without a model mounted on it) to obtain information on support interference effects. Repeat runs were focused at various separation locations and spaced throughout the course of the test to provide a measure of within-test repeatability to aid in uncertainty estimates. 
Comments: Over 1000 proximity data points were collected at transonic conditions. Several aspects of proximity testing at transonic conditions proved challenging. Higher than expected static and dynamic loading on the rig led to a redesign of its fairing and a limitation on its vertical movement. Conversely, tunnel blockage issues precluded testing at subsonic Mach numbers higher than 0.8. Stream-wise movement of the fixture presented a floor seal issue, (due to a large pressure differential between tunnel flow and the plenum) which required several in-situ design iterations to solve. When mounted on a blade support, dynamic loads on the lower model exceeded balance limits in yaw and roll for Mach numbers above 0.8. A stiffer blade/sting support was installed that helped alleviate these lateral dynamics. The area of greatest concern for testing at these conditions is the potential interference effect of the separation rig on model aerodynamics and thus proximity increments. This data set is yet to be fully investigated and thus further comments and conclusions will be reserved for future reports. It is expected that complementary computational fluid dynamic simulations will provide additional insight into this transonic data set.

\section{Computational Methods}

The wind tunnel tests discussed above provide static aerodynamic data at specified orientations of the two bodies undergoing separation. This data is typically incorporated into the engineering evaluation of unsteady maneuvers by constructing aerodynamic databases and performing trajectory integration through these databases using a tool such as SepSim in conjunction with ADAMS, as discussed in the following section on Engineering Methods. Computational fluid dynamics contribute to the simulation of these events by the generation or refinement of (static) aerodynamic databases, and by simulation of the fully unsteady separation event.

Computational simulation of flows with dynamic motion (e.g. store separation problems) have been successfully analyzed by a number of methods. While the approaches used here are not new, this effort, when completed, will compare computational and experimental aerodynamic forces and moments at a variety of Mach numbers for the separation of two bodies of similar size and mass. As of this writing, the longitudinal dynamics for Mach 3 separation of the belly-to-belly LGBB configuration has been simulated.

\section{Background}

In the engineering evaluation of unsteady maneuvers, such as stage separation or aborts, the large number of variables to be considered leads to the use of Monte Carlo techniques and integration of vehicle motion using aerodynamic databases derived from steady-state simulation (experimental or computational). Such variables include flight conditions such as altitude, speed and flight path angle, and initial separation conditions such as orientation, relative velocity, and mechanical forces and constraints. Additional aerodynamic variations may come from control surface deflections or the use of reaction control jets or separation motors.

While traditionally the majority of information in aerodynamic databases originates from wind tunnel-derived force and moment measurements, the aerodynamics of multiple bodies in proximity allows computational methods to contribute data in a variety of situations, including cases where wind tunnel data is not available (such as very close proximity, or where an extension or refinement of the parameter space is desired after the test is completed). Corrections to the data due to wind tunnel mounting effects, differences in flow conditions between wind tunnel and flight, or plume effects may also come from CFD.

These contributions require a significant number of steady-state simulations, with variations in the relative positions of the bodies. As such, a range of computational techniques, varying in cost (or time) and fidelity is desired, but the uncertainties associated with each method must be understood. Computational methods used in the present study include an inviscid (Euler) flow solver and a viscous (Navier-Stokes) flow solver. (In related work, an approach for automating the use of CFD in generating aerodynamic databases was developed in Reference 18. The same Euler and Navier-Stokes flow solvers were used on a single-body LGBB configuration.)

Some aspects of the separation dynamics may depend on unsteady aerodynamics, however. In order to evaluate these effects, CFD can be used to model the unsteady motion of the vehicles, simulating a dynamic separation process. While this takes somewhat more computation than a steady-state case, it allows the simulation of a specific separation scenario, which can then be compared to prediction of the same event from trajectory integration using the aerodynamic databases. Both the separation trajectories and the aerodynamic force contributions to the separation can be compared, allowing an assessment of unsteady effects. If significant, these effects can then be included as uncertainties in the Monte Carlo analysis.

As part of this research effort, both steady and unsteady CFD simulations will be performed. Validation of the computational approaches will involve comparison of computed aerodynamic force coefficients with wind tunnelderived values, as well as comparison of computed separation trajectories using aerodynamic forces from the various sources. The effect of uncertainties in the aerodynamic forces on the trajectory must be evaluated in order to 
judge the usefulness of each tool. The computational tools being investigated here include Cart3d and FlowCart (a Cartesian grid generator and companion Euler flow solver), and OVERFLOW (a Navier-Stokes flow solver). Details of these tools are discussed in the next section.

\section{Computational Codes}

For the present study, a significant effort has been expended on merging two existing versions of the OVERFLOW Navier-Stokes flow solver. The resulting code is referred to as OVERFLOW 2, and includes the capabilities and features of OVERFLOW-D and OVERFLOW Version 1.8. The Chimera overset structured grid scheme is employed, ${ }^{19}$ which is well suited for multi- and moving-body applications because the grids attached to each body need only be reconnected when the bodies are moved, rather than being regenerated. The OVERFLOW$\mathrm{D}$ code is the result of extensive development for a dynamic, moving-body simulation capability. ${ }^{20,21,22}$ This capability has been demonstrated on a number of applications, including store separation, rotorcraft, and missile problems. OVERFLOW-D includes 6-degree-of-freedom dynamic motion, automatic background grid generation, fast hole-cutting and grid connectivity, and parallel computation via the Message Passing Interface (MPI) library. In comparison, the standard OVERFLOW flow solver (versions $1.6-1.8)^{23,24}$ has been used for applications such as launch vehicles, subsonic transports, and hypersonic stage separation. Enhancements to this code have included grid sequencing and multigrid acceleration, low-Mach preconditioning, multiple species capability, implementation of several 1- and 2-equation turbulence models, and addition of Newton sub-iteration and dual time-stepping algorithms. Parallel computation has been accomplished using multi-level parallelism (MLP) and MPI. Of specific interest here is the use of multigrid and grid sequencing for faster convergence of steady-state problems, and the combination of dual time-stepping with OVERFLOW-D capabilities for more efficient simulation of moving-body problems.

For inviscid analyses, the Cart3d unstructured Cartesian grid generator ${ }^{25}$ and the FlowCart Euler flow solver $^{26,27,28}$ have been used. Cart3d is particularly amenable to complex configurations because of its ease of use in generating grids, and FlowCart is capable of producing flow solutions significantly faster than a Navier-Stokes solver such as OVERFLOW. In supersonic flows, normal force and pitching moment can often be predicted with excellent accuracy using inviscid methods. Even axial force values are generally accurate if dominated by pressure effects. Axial force can also be easily adjusted for viscous drag. Inviscid calculations are not able to predict shockinduced flow separation, or separation from a smooth surface, for example on a wing with a rounded leading edge. In transonic flows, inviscid simulations will tend to have shock waves too far aft due to the lack of boundary layer displacement, resulting in errors in normal force and pitching moment.

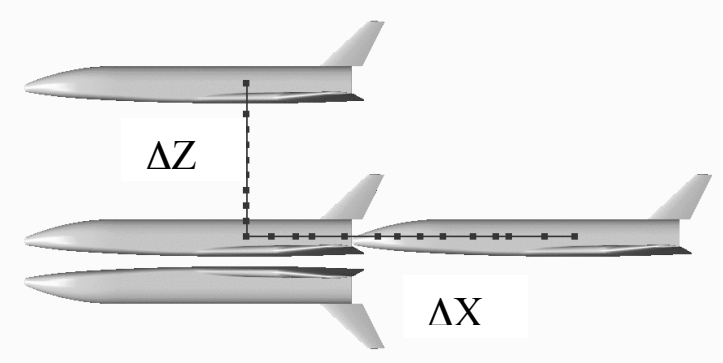

Figure 14. Orbiter and booster relative positions for sweeps in $\square \mathrm{X}$ and $\square \mathrm{Z}$, used in comparisons of aerodynamic forces

\section{Computational Results}

Euler and Navier-Stokes flow simulations have been performed for over 100 relative positions of the LGBB orbiter and booster, matching cases run in the Langley Unitary Plan Wind Tunnel (UPWT). Wind tunnel flow conditions at Mach 3 have been used, but the configuration represented in the computations is that of flight (no blade or sting supports, no plume simulation). Static aerodynamic coefficients are plotted for sweeps in the $\mathrm{X}$ - and Z-directions from the mated position, as shown in Figure 14. In Figures 15 and 16, aerodynamic coefficients of normal force $\left(\mathrm{C}_{\mathrm{N}}\right)$, axial force $\left(\mathrm{C}_{\mathrm{A}}\right)$, and pitching moment $\left(\mathrm{C}_{\mathrm{m}}\right)$ for the booster and orbiter are plotted. Values from the wind tunnel measurements and CFD predictions are compared, showing good agreement in both trends and absolute values. Three discrepancies are noted. First, the booster normal force from the wind tunnel and CFD differ as the booster traverses aft from $\square \mathrm{X} / \mathrm{Lref}=1 / 2$ to 1 . This may be due to wind tunnel support interference, and will be investigated in the future. Second, in both $\square X$ - and $\square Z$-sweeps, orbiter forces display a noticeable offset between computation and wind tunnel. In the wind tunnel, the orbiter was supported by a nonmetric blade mount, similar in cross-section and mounting location to the vertical tail. If the tail force contributions are removed from the OVERFLOW and Cart3d results, excellent agreement is obtained. Finally, the Cart3d and OVERFLOW axial forces are offset, due to the viscous drag contribution not being represented in the Cart3D solutions. 


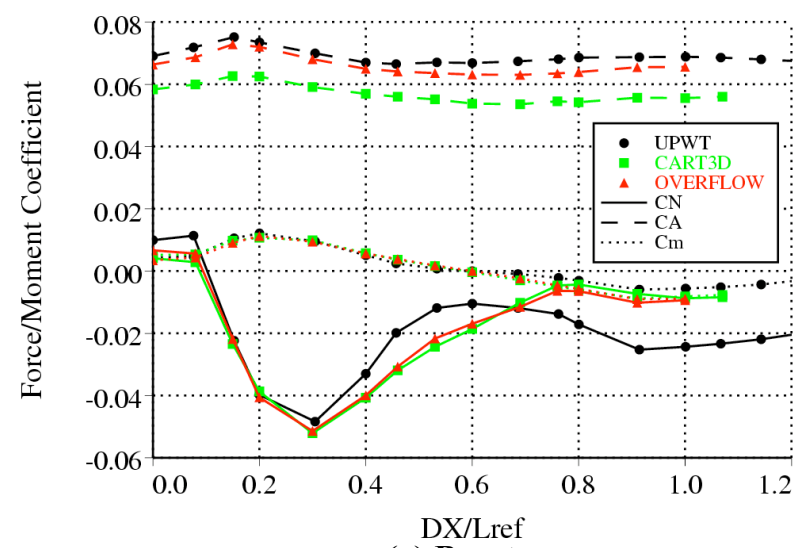

(a) Booster

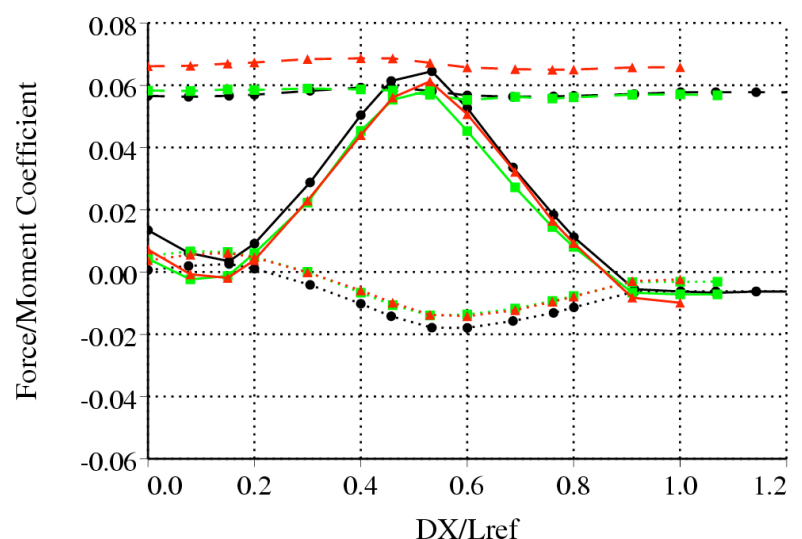

(b) Orbiter

Figure 15. Comparison of wind tunnel and CFD aerodynamic forces for $\square \mathrm{X}$-sweep

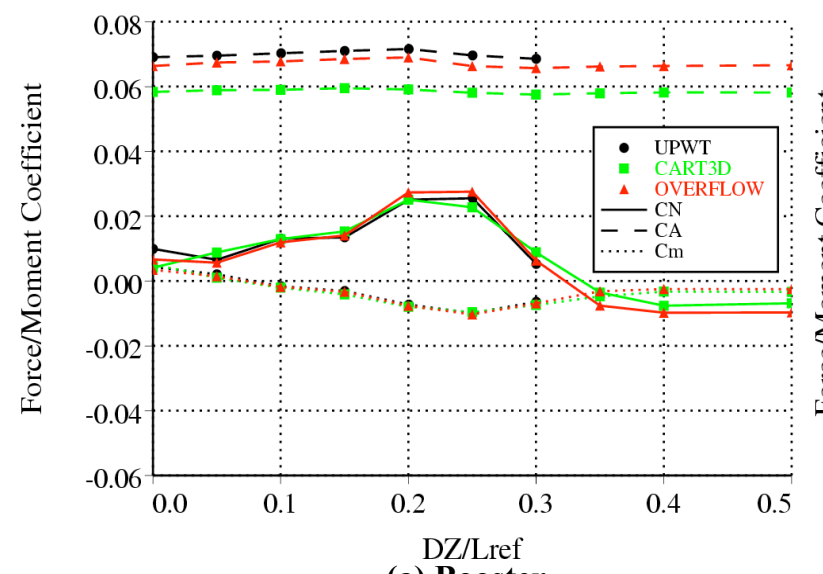

(a) Booster

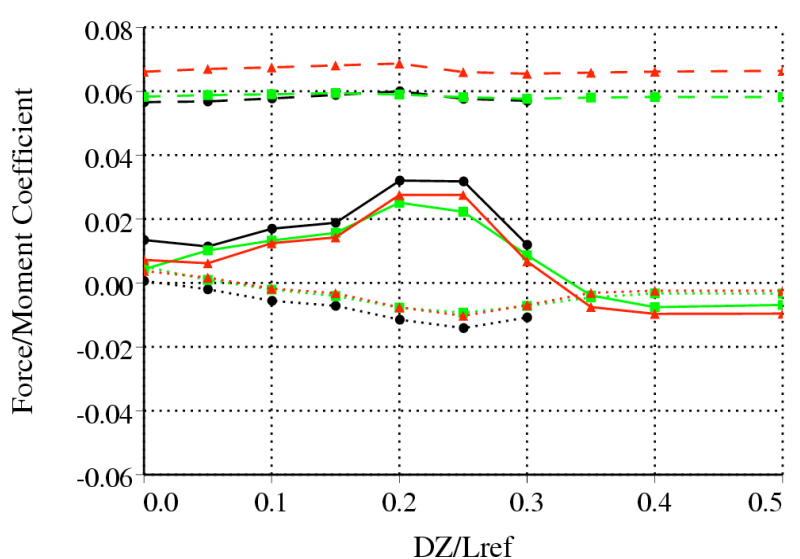

(b) Orbiter

Figure 16. Comparison of wind tunnel and CFD aerodynamic forces for $\square \mathrm{Z}$-sweep

In addition to static calculations, time-accurate, moving body computations were performed using OVERFLOW 2. The dual time-stepping scheme was used, with $2^{\text {nd }}$-order accuracy in time. Ten sub-iterations were used per physical time-step, and the simulation was started from the steady-state mated solution. The dynamic scaling was set to simulate a flight condition of $85,000 \mathrm{ft}$. altitude and a 45 -degree flight-path angle, with the booster on the bottom. Specific choices of booster mass, moments-of-inertia and center-of-gravity were input. No initial separation velocity or prescribed forces were applied, and the orbiter was held fixed. A total time of $2 \mathrm{sec}$. was simulated, with a physical time-step of $0.01 \mathrm{sec}$. The calculated separation trajectory is plotted in Figure 17, first showing the position of the booster relative to the orbiter, and then showing the change in offset and angle-of-attack with time. By the end of $2 \mathrm{sec}$., the aerodynamic forces in the X-and Z-directions on the booster are comparable to the gravity forces in the same directions, given the "heads-down" orientation of the booster. Aerodynamic coefficients along this trajectory are plotted in Figure 18(a), compared to values interpolated from the computational matrix of static values from OVERFLOW at the same offset and orientation. Large differences in normal force are noted, which are not due to time-step sensitivity or database interpolation error. While the separation velocity is small compared to the free stream velocity (on the order of 3\%), it has a significant effect on the effective angle-of-attack of the booster. At $2 \mathrm{sec}$. for example, the relative velocity of the booster lowers the effective angle-of-attack by 1.4 degrees, accounting for the majority of the difference in forces. Care must also be taken to account for the effect of relative velocity on dynamic pressure when converting booster aerodynamic forces to coefficient form. Once these corrections have been made, much better agreement is achieved, as shown in Figure 18(b). The remaining difference in normal force has been found to be due to linear interpolation error (the computational matrix is coarser than the wind tunnel test matrix in $\square \mathrm{X}$ and $\square \mathrm{Z}$ ). This agreement between steady and unsteady coefficients demonstrates that unsteady aerodynamics does not play a significant role in this (relatively benign) separation at Mach 3. 
These calculations show a significant capability of CFD in contributing to stage separation and abort simulation, but additional work remains to be done. In addition to pursuing the discrepancies noted above, an evaluation of trajectories computed using data from various sources is needed. Examination of results at transonic and hypersonic conditions must still be made, along with the evaluation of a newly-available dynamic moving-body capability in FlowCart. The ability for moving control surfaces coupled with control system logic must also be included in the CFD codes for a full simulation capability to be available.
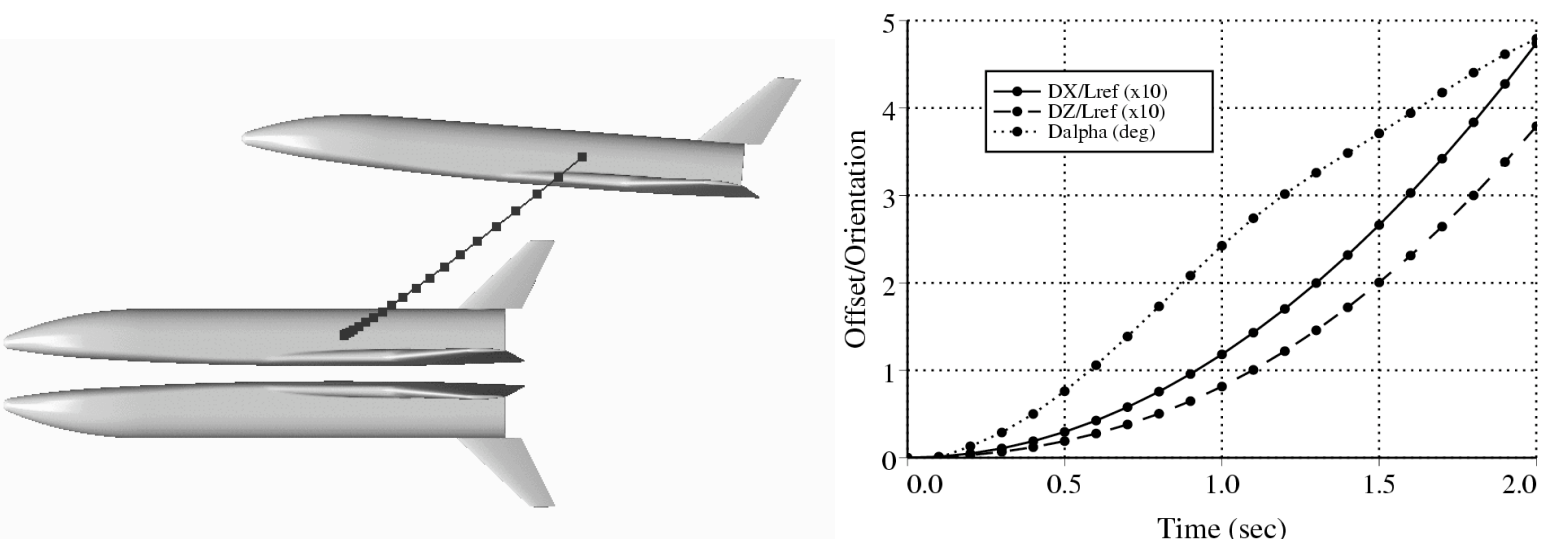

Figure 17. Relative position of booster during separation (symbols represent 0.1 sec. time intervals)

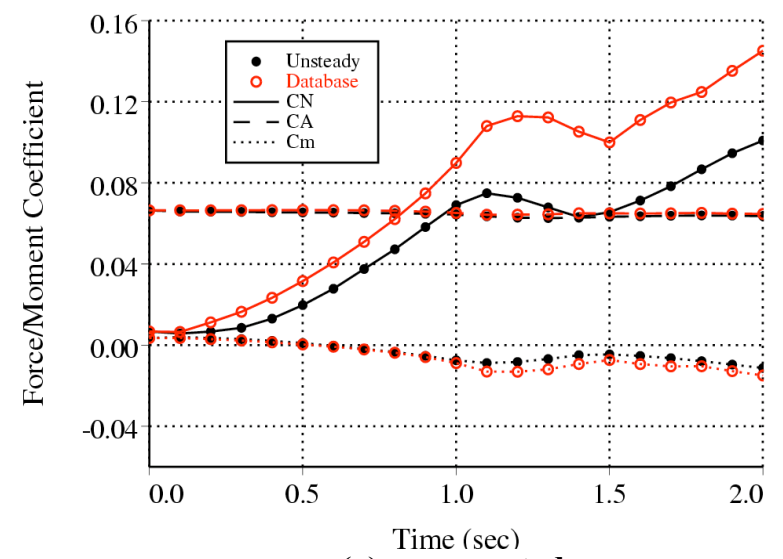

(a) uncorrected

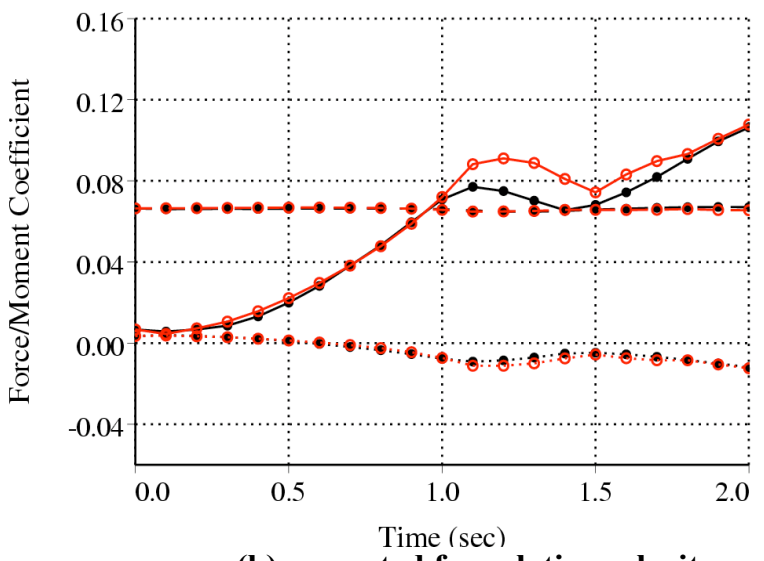

(b) corrected for relative velocity

Figure 18. Comparison of booster aerodynamic forces from unsteady CFD and (static) database interpolation along the separation trajectory

\section{Engineering Methods}

The engineering level tool development activity consists of two parts:

(1) APAS-MB (Aerodynamic Preliminary Analysis System Multi-Body) Code Enhancement: The objective of this effort is to develop an engineering level aerodynamic multi-body analysis code for estimating proximity aerodynamic coefficients in stage separation environment.

(2) SepSim Software Development: The objective of this activity is to develop a software tool for dynamic simulation of the vehicle motion(s) starting from attached condition and ending when the two vehicles either make a re-contact (failure) or move apart safely (successful stage separation).

\section{APAS-MB Code}

$\mathrm{APAS}^{29,30}$ is an engineering level code originally developed by Rockwell International (now Boeing) under contract with NASA Langley Research Center during 80s and 90s. APAS is an interactive computer code capable of providing engineering-level estimates of aerodynamic coefficients from subsonic to hypersonic speeds. APAS run 
times are of the order of minutes. This type of rapid turn around capability of APAS makes it a very useful tool for conceptual level system analyses. APAS consists of three modules: (1) the executive module which handles geometry modeling, pre- and post-processing of analysis runs and results, (2) the Unified Distributed Panel (UDP) module that is used for subsonic and low supersonic analysis and (3) the Hypersonic Arbitrary Body Program (HAPB) module for high supersonic and hypersonic speeds. Technical specifications and engineering models for these modules are described in References 29 and 30.

APAS was essentially developed to analyze wing-body-tail type configurations. The code has also been used to analyze single-body configurations with small-scale, externally-mounted stores. Even though the methodologies existing in APAS can be used for multi-body analyses, the APAS code was not designed to handle like-scale, multibody configurations. The aerodynamics of multi-bodies in stage separation environment is quite complex and is dominated by mutual interference effects that are characterized by multiple shockwaves and their reflections, shock boundary layer interactions, and flow separations. The linear, panel type methods existing in APAS may not be capable of capturing all the physics associated with such complex flows. Such methods are known to perform well for aircraft store separation type problems where the store is much smaller than the parent aircraft. The objective of the present study is to determine whether the APAS methods with new supersonic triplet capability ${ }^{31}$ are capable of capturing the first order effects in TSTO stage separation for Mach numbers from 1.2 to 6.0 and providing some estimates that may serve useful for system-level stage-separation analysis.

The multi-body code development was also done in two parts consistent with the structure of the APAS code, i.e., a separate multi-body capability in UDP and HABP. In UDP, a provision exists to compute the perturbation velocities at specified number of off-body field points. For the development of multi-body code, this provision was invoked with the assumption that the field points for the first body would be the panel control points of the second body and vice versa. Initially, the UDP-MB code solves for the strength of singularities on each body ignoring the presence of the other body and in this process, it also calculates the perturbation velocities at the field points (control points on the other body) and vice versa. Then, in subsequent iterations, the strengths of these singularities on each body are recalculated considering the perturbation velocities due to the other body. This process continues until the computations converge within a specified accuracy. HABP methods are mainly impact type methods and do not consider mutual interference between panels. In the impact methods there is no explicit description of the leading edge bow shock wave or any secondary shock wave or expansion waves that may exist on the body. Thus, to account for the influence of shock wave of one body on the other body, the shape of the shock wave for each body has to be determined outside HABP and supplied to the HABP-MB code as an external input. For a TSTO configuration the user input consists of two shock wave shapes, one for the booster and the other for the orbiter. This information may be empirical or may be based on existing information on similar body shapes. Further, in HABPMB it is assumed that the two shock waves simply "go through" each other (as though one shock wave does not know the existence of the other) and then may strike the other body. It is assumed that on striking the other body, each shock wave is "swallowed", i.e., there are no subsequent reflections. The region of the body ahead of the shock intersection point is treated as though it existed in the free stream by itself, and the region aft of the shock intersection point is assumed to be operating in a free stream having the flow properties that would exist behind the intersecting shock wave.
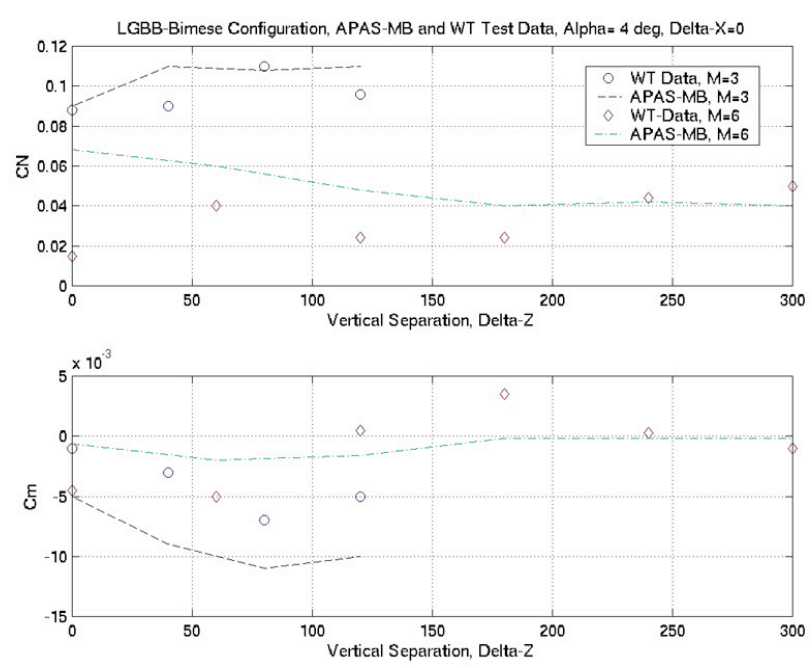

Figure 19. Comparison of APAS and wind tunnel test data
A comparison of the APAS-MB predictions and the wind tunnel test data at Mach 3 and Mach 6 for the LGBB configuration at $\square=4$ degrees and $\square \mathrm{X}=0$ is presented in Fig. 19. It is observed that the predicted normal force coefficient is in only fair agreement with the measured test data and the predicted pitching moment coefficient differs significantly from the test data, especially for the Mach 6 case. Significant improvements in shock wave modeling would be required to attain an acceptable level of fidelity for general applications.

\section{$\underline{\text { SepSim }}$}

The Stage Separation Simulation (SepSim) is an engineering-level tool designed for the dynamic simulation of nominal or abort staging

American Institute of Aeronautics and Astronautics 
of multi-stage launch vehicles. SepSim is based on the ADAMS/Solver ${ }^{\circledR}$ and is developed and implemented by AMA (Analytical Mechanics Associates) under contract with NASA Langley. The Automatic Dynamic Analysis of Mechanical Systems (ADAMS) is widely-used commercial software package for solving multi-body dynamics problems. ${ }^{32}$ The SepSim works in Matlab environment to take advantage of Matlab analysis tools and graphic capability. The current version of SepSim has the capability to simulate the staging of two vehicles at a time such as a TSTO type configurations consisting of a booster and an orbiter. It has the capability to model multiple attachment points, reaction jets or piston type devices, closed-loop flight control, standard atmosphere, winds, engine plumes etc. It is also configured for Monte Carlo studies.

SepSim is developed with the objective of providing a user-friendly interface to ADAMS for multi-body dynamics problems. All the user inputs are specified in a file called sep.dat. These inputs include vehicle mass and inertia properties, initial conditions such as staging altitude, velocity, flight path angle, angles of attack of each vehicle, location and nature of attachment joints, simulation controls, events etc. The stage-separation aerodynamic data tables are input separately as user input subroutines. A Matlab-based front-end translates these user inputs in a form needed to setup and execute ADAMS. The SepSim also features additional Matlab-based scripts to facilitate the post-processing of simulation results from ADAMS. This architecture is illustrated below in Figure 20.

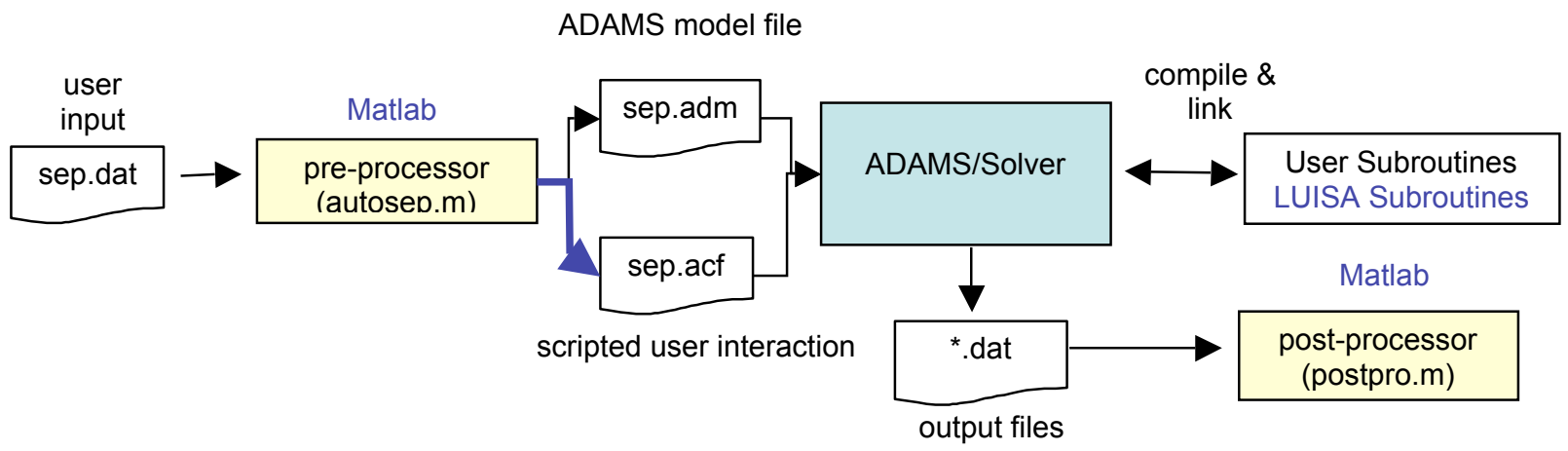

Figure 20. SepSim Architecture.

A brief description of this architecture is described below:

ADAMS/Solver: ADAMS is a numerical analysis program for building and evaluating mechanical system models. User defined models may include point masses, rigid bodies and general differential equations. A number of explicit and implicit integration schemes are available in ADAMS for solving the governing equations of motion.

User Interface: ADAMS is an extremely flexible modeling and simulation environment. Because of this high level of flexibility, a significant degree of customization is required in order to configure ADAMS for a specific dynamical system. SepSim provides a simple user interface which consists of only those modeling options in ADAMS that are necessary for the simulation of stage separation of two vehicles at a time. This User Interface consists of a Matlab-based pre-processing routine autosep. $m$ which generates ADAMS input files sep.adm and sep.acf. These two files contain ADAMS model and command file entries.

User Subroutines: In ADAMS, some of the logic required to manage various user options and model vehicle subsystems needed for the simulation of stage separation are not supported directly. The available functions and statements in ADAMS are too complex to implement for the stage separation scenario. In SepSim, the ADAMSprovided hooks are used to link the specially developed codes or user subroutines. One such example is the implementation of stage-separation aerodynamics data tables that require multi-dimensional table lookup functions. This is accomplished by linking a library called the Look-Up Integrated Stand Alone (LUISA) to the ADAMS solver. The LUISA is used in the POST (Program to Optimize Simulated Trajectories). ${ }^{33}$

A brief description of various subsystems implemented in SepSim is described below:

Aerodynamics: The interference (proximity) and free stream aerodynamic data are input in the form of several multi-dimensional tables and implemented using LUISA as stated above. The following mathematical model is used to transition from interference (proximity) data to the free stream data as the vehicle move apart:

$F_{i}=q S_{r e f}\left[k_{1} C_{i, b}+\left(1 \square k_{1}\right) C_{i, \text { int }}\right]+\square C_{\square}$. Here, $F_{i}$ denotes a force such as lift or drag or side force, $\quad q$ is the dynamic pressure, $S_{r e f}$ is the reference area, $\quad C_{i, b}$ is the free stream aerodynamic coefficient, $\quad C_{i, \text { int }}$ is the 
interference or the proximity aerodynamic coefficient, $k_{1}$ is the interpolation factor for transition from the interference aerodynamics $\left(k_{1}=0\right)$ to the basic or interference-free aerodynamics ( $k_{1}=1$ ), and, $\square C_{\square}$ is the increment due to control surface deflection. In the transition region, $k_{1}$ is assumed to vary linearly from 0 to 1 . Note that in addition to angle of attack and Mach number, $C_{i \text {,int }}$ also depends on the relative location of the two vehicles in axial and normal directions. A similar formulation is used for the pitching, rolling or yawing moment.

Joints (Constraints): In SepSim, a number of joints are available to specify the coupling of the two vehicles. The available options include translational, revolute and spherical joints. At time zero, it is assumed that the two vehicles are fixed together. This can be designated as event 1 . Suppose the constraints (joints) are released at a specified time and the vehicles are let go. This can be designated as event 2 .

Separation Forces: In principle, two types of separation forces may be applied to the vehicles as part of the separation strategy. Such a force could be an action only type or an action/reaction type force. The action only type is used to emulate a thruster type force, whereas the action/reaction type is used to emulate a piston-type separation mechanism. Both these options are available in SepSim.

Control Systems: In the current version of SepSim, the Proportional and Derivative (P-D) feedback control law options are provided for each vehicle.

Actuators: Actuator model options include first order model as defined by frequency and position limits, second order model defined by natural frequency and damping with optional position limits and second order model with natural frequency, damping, position and rate limits.

Propulsion: In the current version, the thrust for each vehicle, if any, is assumed to be constant in magnitude and direction during the staging event. The user can specify the magnitude and direction of the thrust for each of the vehicle.

Atmosphere: Atmosphere options include the US Standard 1962 and GRAM '95 atmospheres.

Separation Strategy: The complete stage separation process can be described as a set of events. In the current version, events can be used to trigger the release of specific degrees of freedom of joint(s) or trigger the release of the remaining degrees of freedom or trigger the start of the separation piston or a thruster force or trigger the end of the separation piston or termination of thruster force or engage the vehicle 1 feedback control system or engage the vehicle 2 feedback control system etc.

Some sample results of the simulation for LGBB bimese configuration using Mach 6 wind tunnel test data are presented in Figure 21. The front attachment (constraint) was released at $t=1.0 \mathrm{sec}$ and the booster was allowed to
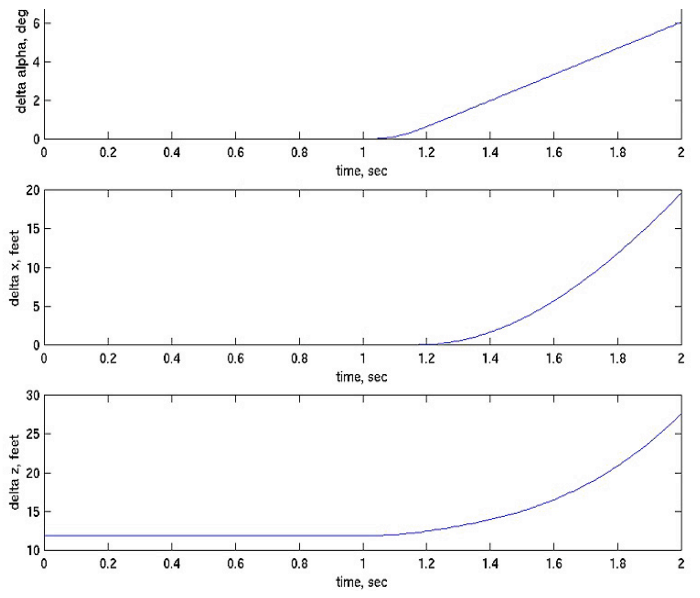

Figure 21. SepSim Example rotate about the aft attachment. At $\mathrm{t}=1.2 \mathrm{sec}$, the vehicle was released from the aft attachment and was free to go. The simulation results are presented up to $\mathrm{t}=2 \mathrm{sec}$. The results for $\mathrm{t}>2 \mathrm{sec}$ indicated that the two vehicles separated safely. It may be noted that the dynamic pressure used in this simulation corresponds to an altitude of $85000 \mathrm{ft}$, which is higher than that would exist typically for a Mach 6 staging.

\section{Visualization of SepSim Simulation Results}

The output from the SepSim simulation are used in the so called Synergistic Engineering Environment (SEE) for animation of the complete stage separation scenario and collision detection, if any, or potential plume impingement on any of the vehicles during staging. The SEE is a visualization and analysis environment for spacecraft design and mission planning. ${ }^{34}$ For application of SEE to a TSTO stage separation, the two stages are considered as two separate spacecraft models. Each spacecraft's position and orientation are defined by the state variables provided in the output of the SepSim. Also available in the output from the SepSim are the location, orientation, and firing data for each thruster, for each vehicle. The actual shape of each plume is generated off-line (outside SEE and SepSim) using the FORTRAN-based plume program plume.for. Then, in SEE, the plume shape is combined with the geometry models for each vehicle. The geometries were generated using the IDEAS MasterSeries CAD software. The vehicle geometry was exported from the CAD system using the STL binary file format, which can be read by the SEE. A summary of the data integration in SEE setup is shown below in Figure 22. 


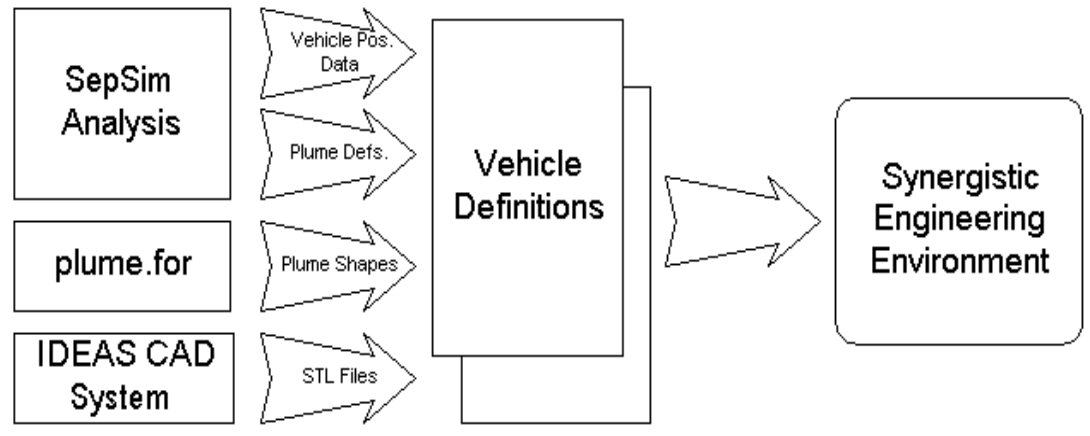

Figure 22. SepSim SEE Data Integration
Upon integration of all the data into the SEE, the user can visualize the entire stage separation process at any desired time rate. The SEE has the capability to set up a proximity analysis so that the user can monitor the distance between the vehicles. The user can also monitor the plume attached to one spacecraft against the geometry of the other spacecraft.

\section{Website Development}

In the stage separation research program, a concerted effort has been made to coordinate experimental, computational, and engineering method tool development processes. A key part of this coordination is the follow-on organization and archival of data generated from these tools into a database accessible to the user community. Webbased archival tools are ideal for this type of continually growing repository of data and tool development information.

The web-based software AEROCOMPASS ${ }^{35}$, previously developed at LaRC, is an integrated set of project/testrelated tools and applications that is ideally suited for this type of database development and access. A key feature is the user-friendly document management system that enables groups of users in multiple geographic locations to share and manage a variety of document types and information. Figure 23 shows the existing home page on AEROCOMPASS for the stage separation website. The website will act as a repository for experimental,

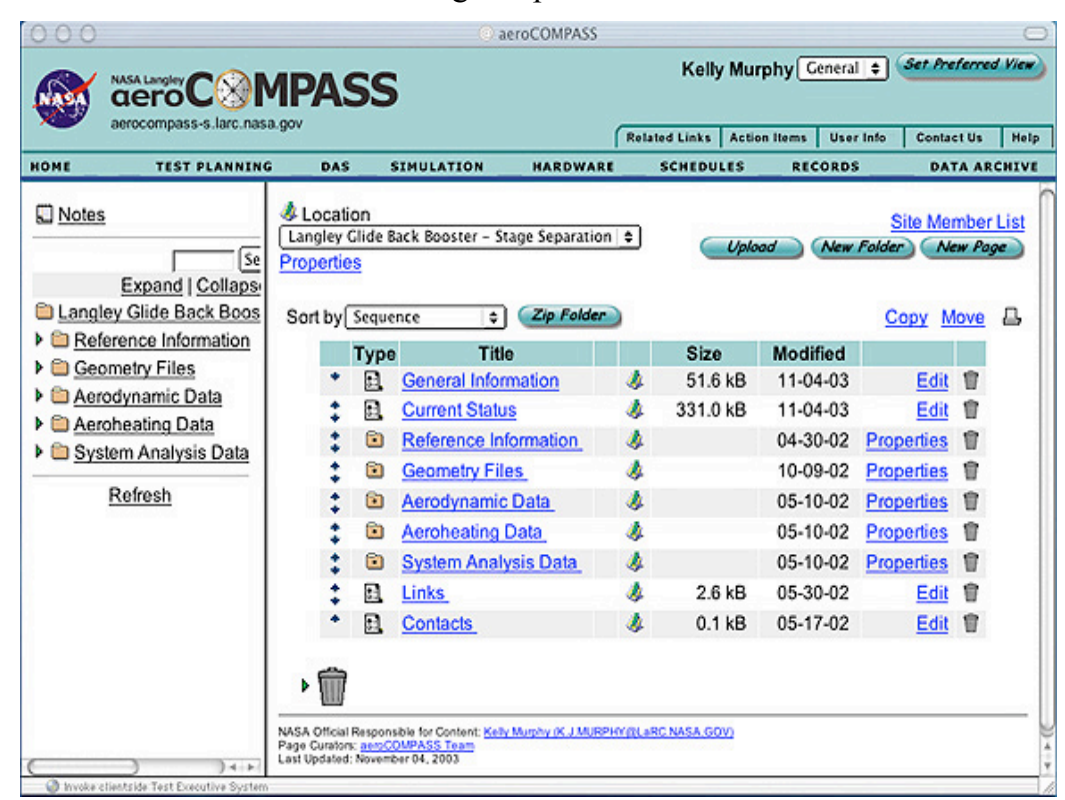

Figure 23. Stage Separation Website Home Page on AEROCOMPASS computational, and system analysis data, as well as all supporting information necessary for the understanding and use of this data. AEROCOMPASS allows a central location for configuration and file reference information, geometry files, as well as background information on codes and facilities. It's also an easy way to provide updated status information to the general user community. Any approved personnel can be given an account on the AEROCOMPASS system at the discretion of the responsible NASA official. The AEROCOMPASS software also allows permissions to be given on a folder basis, e.g. competing contractors can be given access to the site in a limited form if there are competition sensitive materials on the site.

\section{Summary and Conclusions}

Development of synergistic stage separation tools is underway at NASA in the experimental, computation, and engineering methods arenas to address issues associated with nominal and abort stage separations of like-scale, wing-body two-stage-to-orbit concepts. A common generic bimese configuration was used to exercise and compare 
these tools. Exploratory experimental aerodynamic data has been acquired in the transonic, supersonic, and hypersonic speed regimes. Separation hardware and appropriately scaled models now exist for each test regime for generation of two-body interference data. Supersonic testing was accomplished in Langley's Unitary Plan Wind Tunnel leveraging the existing remote movement capability of the facility's main support strut and adding a newlybuilt fixed sidewall support strut. Hypersonic testing was conducted in Langley's 20-Inch Mach 6 Air Tunnel using a previously built, manual-set, multi-body separation rig. Tests in the Langley's 31-Inch Mach 10 Air Tunnel are planned for Fall 2004. A two-axis remote-driven rig was fabricated for transonic proximity testing in Langley's 16FT Transonic Tunnel. A thorough analysis of stage separation data generated through this tool development program will be reported in future publications. Support interference will be addressed, especially for transonic test conditions. Comparison of experimental proximity increments to computationally-derived data has begun in the supersonic regime with encouraging results.

Computational tool development for stage separation has focused on the merging of OVERFLOW-D movingbody capabilities into a new OVERFLOW 2 Navier-Stokes flow solver, resulting in the capability for more efficient static and dynamic stage separation simulations. Comparisons with the Cartesian-grid Euler method Cart3D/FlowCart has demonstrated the applicability of inviscid methods at Mach 3, which have advantages in setup and execution time when compared to OVERFLOW.

Engineering level tool development activity consists of the modification of the APAS code to estimate proximity aerodynamic coefficients in a stage separation environment and the development of the SepSim software for the dynamic simulation and visualization of vehicle motions in a stage separation scenario. Initial APAS-MB results indicate the need for improved flow field modeling to improve prediction capabilities. Efforts are underway to improve the modeling of shock wave shape, a user-input to the HABP-MB code, which is shown to have a significant influence on resultant aerodynamic interference characteristics.

\section{Acknowledgments}

The authors wish to thank the numerous technicians and engineers at the Unitary Plan Wind Tunnel, the 20-Inch Mach 6 Air Tunnel, and the 16-FT Transonic Tunnel at the NASA Langley Research Center without whose dedication and innovation the experimental test program would not have been possible. Acknowledgement is also extended to Wayne Bordelon and Alonzo Frost at the NASA Marshall Space Flight Center for their early contributions to LGBB proximity test results. The authors would like to acknowledge Reynaldo Gomez of NASA Johnson Space Center for generating the OVERFLOW grid system for the LGBB, as well as generating the Cart3d/FlowCart results shown here. Mr. Gomez has also supplied extensive feedback on approaches to simulating stage separation, and the capabilities of various numerical techniques. Acknowledgement also goes to Robert Meakin and Mark Potsdam for many critical discussions on the various features of OVERFLOW-D, and to William Chan for assistance in coding of moving-body capabilities and post-processing of results from OVERFLOW 2. The authors are also thankful to Martin Hegedus and Mike Mendenhall of Nielson Engineering and Research (NEAR) Inc. for their help in generating APAS-MB results and to Dave Bose, Nathan Hotcho, and Scott Angster of Analytical Mechanics Associates (AMA) for their help in generating SepSim results.

\section{References}

1. NGLT Fact Sheet, http://www1.msfc.nasa.gov/NEWSROOM/background/facts/ngltfacts.pdf, Nov. 2003.

2. Dillenius, M.F.E., Perkins, S.C., and Nixon, D., Pylon Carriage and Separation of Stores, AIAA Progress in Astronautics and Aeronautics:Tactical Missile Aerodynamics-General Topics, M. J. Hemsch, ed., Vol. 141, 1992.

3. Decker, J. P, Aerodynamic Separation Characteristics of Conceptual Parallel-Staged Reusable Launch Vehicle at Mach 3 To 6, NASA-TM X-1051, Langley Research Center, Jan. 1965.

4. Decker, J.P, Gera, J., An Exploratory Study of Parallel-Stage Separation of Reusable Launch Vehicles, NASA-TN D-4765, Langley Research Center, Oct. 1968.

5. Decker, J.P, Aerodynamic Interference Effects Caused By Parallel-Staged Simple Aerodynamic Configurations at Mach Numbers of 3 and 6, NASA TN D-5379, Langley Research Center, Aug. 1969. 
6. Decker, J.P., Wilhite, A.W., Technology and Methodology of Separating Two Similar Size Aerospace Vehicles Within the Atmosphere, L-9805, AIAA $13^{\text {th }}$ Aerospace Science Meeting, Pasedena, CA, Jan. 1975.

7. Craig, M.K., Dresser, H.S., Shuttle Booster Separation Aerodynamics, NASA Center for AeroSpace Information (CASI), pp. 139-157, 1983.

8. Wilhite, A.W., Analysis of Separation of the Space Shuttle Orbiter from a Large Transport Airplane, NASA TM X-3492, Langley Research Center, June 1977.

9. Naftel, J.C., Wilhite, Cruz, C.I., Analysis of Separation of a Two-Stage Winged Launch Vehicle, AIAA Paper 86-0195, Jan. 1986.

10. Naftel, J.C., Wilhite, A.W., Aerodynamic Separation and Glideback of a Mach 3 Staged Orbiter, AIAA Paper 90-0223, Jan. 1990.

11. Naftel, J.C, Private Communication, Sept. 2001.

12. Scallion, W.I., Private Communication, Nov. 2003.

13. Buning, P.G., et al., Compuational Fluid Dynamics Prediction of Hyper-X Stage Separation Aerodynamics, Journal of Space Craft and Rockets, Vol 38, No. 6, 2001, pp.820-827.

14. Bordelon, W.J., Frost, A.L., Reed, D.K., Stage Separation Wind Tunnel tests of a Generic Two-Stage-toOrbit Launch Vehicle, AIAA Paper 2003-4227, July 2003.

15. Erickson, G.E., Overview of Selected Measurement Techniques for Aerodynamic Testing in the NASA Langley Unitary Plan Wind Tunnel, AIAA Paper 2000-2396, June 2000.

16. Micol, J.R., Langley Aerothermodynamic Facilities Complex: Enhancements and Testing Capabilities, AIAA Paper 98-0147, Jan. 1998

17. Capone, F.J., et al., The NASA Langley 16-FT Transonic Tunnel: Historic Overview, Facility Description, Calibration, Flow Characteristics, and Test Capabilities, NASA TP-3521, Langley Research Center, Sept. 1995.

18. Chaderjian, N.M., et al., Automated CFD Database Generation for a $2^{\text {nd }}$ Generation Glide Back Booster, AIAA Paper 2003-3788, June 2003.

19. Steger, J.L., Dougherty, F.C., and Benek, J.A., A Chimera Grid Scheme, Advances in Grid Generation, K.N. Ghia and U. Ghia, eds., ASME FED Vol. 5, June 1983.

20. Meakin, R.L., Object X-Rays for Cutting Holes in Composite Overset Structured Grids, AIAA Paper 20012537, June 2001.

21. Meakin, R.L., Automatic Off-Body Grid Generation for Domains of Arbitrary Size, AIAA Paper 20012536, June 2001.

22. Chan, W.M. Meakin, R.L., and Potsdam, M.A., CHSSI Software for Geometrically Complex Unsteady Aerodynamic Applications, AIAA Paper 2001-0539, Jan. 2001.

23. Buning, P.G., et al., OVERFLOW User's Manual, Version 1.8ab, NASA Langley Research Center, July 2003.

24. Jespersen, D.C., Pulliam, T.H., and Buning, P.G., Recent Enhancements to OVERFLOW, AIAA Paper 970644, Jan. 1997. 
25. Aftosmis, M.J., Berger, M.J., and Melton, J.E., Robust and Efficient Cartesian Mesh Generation for Component-Based Geometry, AIAA Journal, Vol. 36, No. 6, pp. 952-960, 1998.

26. Aftosmis, M.J., Berger, M.J., and Adomavicius, G., A Parallel Multigrid Method for Adaptively Refined Cartesian Grids with Embedded Boundaries, AIAA Paper 2000-0808, Jan. 2000.

27. Murman, S.M., Aftosmis, M.J., and Berger, M.J., Simulations of 6-DOF Motion with a Cartesian Method, AIAA Paper 2003-1246, Jan. 2003.

28. Murman, S.M., Aftosmis, M.J., and Berger, M.J., Implicit Approaches for Moving Boundaries in a 3-D Cartesian Method, AIAA Paper 2003-1119, Jan. 2003.

29. Bonner, E., Clever, E., and Dunn, K., Aerodynamic Preliminary Analysis System II, Part I- Theory, NASA CR 182076, Apr. 1991.

30. Sova, G., and Divan, P., Aerodynamic Preliminary Analysis II, Part II-User's Manual, NASA CR 182077 , Apr. 1991.

31. Woodward, F.A., Development of Triplet Singularity For Analysis of Wings and Bodies in Supersonic Flow, NASA CR 3466, Apr. 1981.

32. Using ADAMS/Solver, Mechanical Dynamics, Inc., 1999.

33. Brauer, G.L., Cormick, D.E., and Stevenson, R., Capabilities and Applications of the Program To Optimize Simulated Trajectories (POST), NASA CR-2770, Feb. 1977.

34. Angster, S., Synergistic Engineering Environment Build II User's Guide Revision E, AMA Report No. 0331, Aug. 2003.

35. AEROCOMPASS Website, http://aerocompass.larc.nasa.gov/Overview/index_HistoricalPerspective.html, Nov. 2003. 